\title{
HANDELSSTRUKTUREN IM OSTSEERAUM \\ IM 12. UND BEGINNENDEN 13. JAHRHUNDERT
}

\author{
ANSÄTZE EINER NEUBEWERTUNG
}

\author{
von Carsten Jahnke
}

Betrachtet man die einschlägige Literatur zur Handelsgeschichte des Ostseeraumes im 12. und 13. Jahrhundert, so wird schnell klar, dass man es in diesem Bereich mit einem Feld der Giganten zu tun hat. Alle großen Hanseforscher der letzten einhundert Jahre haben ihren Beitrag zu diesem Thema geleistet, und spätestens seit den maßgeblichen Arbeiten von Fritz Rörig, ${ }^{1}$ Wilhelm Koppe, ${ }^{2}$ Heinz Stoob ${ }^{3}$ und Erich Hoffmann ${ }^{4}$ hat sich ein allgemeiner Konsens über die ökonomischen Umwälzungen zu dieser Zeit herausgebildet. Nach diesem Bild spielte vor allem der Aufstieg Lübecks nach der so genannten zweiten Stadtgründung 1158/59 eine maßgebliche Rolle dabei, dass sich der Transitverkehr von der Ost- in die Nordsee von Schleswig an die Trave verlagerte und, dass der deutsche Kaufmann seine späterhin unbestreitbare Vorrangstellung im Handel dieses Raumes erringen konnte. Lübeck wird dabei als Schlüssel zur „Hanseatisierung“ des Ostseeraumes gesehen.

Dieses Bild ist so wirkungsmächtig und so allgemein akzeptiert, dass zum Beispiel archäologische Ausgrabungsergebnisse fast ausschließlich unter diesem Diktum interpretiert werden, selbst, wenn man dafür die Ergebnisse das eine oder andere Mal erheblich biegen muss, damit sie sich in die Vorstellung einpassen.

\footnotetext{
' U. a. Fritz RÖRıG, Die Entstehung der Hanse und der Ostseeraum, in: Wirtschaftskräfte im Mittelalter, hg. von Paul Kaegbein, Köln 1959, S. 542-603.

${ }^{2}$ Wilhelm KOPPE, Schleswig und die Schleswiger (1066-1134), in: Städtewesen und Bürgertum als geschichtliche Kräfte, Gedächtnisschrift für Fritz Rörig, hg. von Ahasver von Brandt und Wilhelm Koppe, Lübeck 1953, S. 95-120.

${ }^{3}$ Heinz Sтоов, Schleswig-Lübeck-Wisby, in: ZVLGA 59, 1979, S. 7-27.

${ }^{4}$ Unter anderem Erich HoFFMANN, Schleswig und Lübeck im 12. und 13. Jahrhundert, in: BSStG 26, 1981. S. 26-38. DERS., Die schrittweise Ablösung Schleswigs durch Lübeck als wichtiges Seehandelszentrum an der westlichen Ostsee (ca. 1150-1250), in: Lübecker Schriften zur Archäologie und Kulturgeschichte 7, 1983, S. 39-46.
} 
Besonders kritisch wird der Konsens spätestens dann, wenn in den Grundannahmen implizit - und heute natürlich ungewollt - Vorstellungen von germanischer Überlegenheit mitschwingen. So stieß nach diesem Bild, überspitzt und sehr polemisch formuliert, 1158 der westfälischdeutsche Kaufmann mit dem Koggen unter dem Arm von Lübeck aus sofort das Tor zum Ost-Westhandel auf, um mit seinem überlegenen Know-how die Konkurrenz von hinten aufzurollen und sofort die Herrschaft im Ostseeraum zu übernehmen.

Diese Vorstellung krankt allerdings, wenn man sie im Lichte der historischen aber auch der archäologischen Quellen betrachtet, gleich an mehreren Punkten. So weisen erstens die schriftlichen Quellen sehr deutlich darauf hin, dass sich die Veränderungen im Ostseeraum prozessual und zwar vom ersten Drittel des 12. bis zum zweiten Drittel des 13. Jahrhunderts vollzogen haben. Zweitens ist die Grundannahme, dass Lübeck als Transitstadt für den Ost-Westverkehr gegründet wurde ebenso falsch, wie eine entsprechende Vermutung für Hamburg. Wie zu zeigen sein wird, entwickelte sich der Ost-Westverkehr zwischen Hamburg und Lübeck erst sekundär am Ende des 12. Jahrhunderts und sollte erst im ersten Drittel des 13. Jahrhunderts die Bedeutung einnehmen, die unsere Vorstellungen bisher geprägt hat. Dieses hat drittens natürlich erhebliche Auswirkungen auf die Beurteilung des Transitverkehres zwischen Hollingstedt und Schleswig und für die Bedeutung des Schleihafens für den nordeuropäischen Fernhandel. Viertens ist auch nach den praktischen Voraussetzungen für den Ostseehandel im 12. Jahrhundert zu fragen und in diesem Fall sehr konkret danach, wie die deutschen Kaufleute ihre Waren überhaupt aus Lübeck resp. Schleswig gen Osten heraus bekamen. In diesem Bereich muss der sehr emotional aufgeladene Begriff des Koggen und seiner angeblich technischen Überlegenheit überaus kritisch hinterfragt werden, und es muss ebenso gefragt werden, ob der sächsisch-westfälische Kaufmann, der nach Lübeck kam, überhaupt Vorstellungen vom Schiffbau und Schiffbesitz mitbrachte. ${ }^{5}$ Generell muss dann fünftens die Rolle der alten Kaufmannschaft im Ostseeraum, d.h. die der Gotländer und vor allem die der in den Knudsgilden organisierten Skandinavier, noch einmal unter dem Lichte der gewonnenen Erkenntnisse analysiert werden, um so vielleicht zu einem ausgewogeneren Bild der Entwicklungen zu gelangen."

\footnotetext{
${ }^{5}$ Wie ich erst nach Abschluss dieses Beitrages erfahren habe, stellte schon Gunnar BoLIN, Stockholms Uppkomst: Studier och undersökningar rörande Stockholms förhistoria. Uppsala 1933, S. 181-184 und 403-409, diese Frage und beantwortete sie in sehr eindruicklicher Weise im Sinne dieses Beitrages, gegen die damals gängige Forschung. Seine Erkenntnisse wurden aber als irrelevant abgetan. Vgl. Paul HeINSIUS, Das Schiff der hansischen Frühzeit. Köln 1986, S. 12f. und passim.
} 
Der Ausgangspunkt der Entwicklung zu Beginn des 12. Jahrhunderts ist ebenso klar, wie das Ende am Ausgang des 13. Jahrhunderts. Die Frage ist jedoch, welche Faktoren als Katalysatoren der Entwicklung gewirkt und welche strukturellen Veränderungen dazu beigetragen haben.

\section{Der Handel im Ostseeraum zu Beginn und zur Mitte des 12. Jahrhunderts}

Der Fernhandel rund um die Ostsee wird schon seit Ausgang des Hochmittelalters durch drei wesentliche Faktoren bestimmt. Zum einen durch das Russisch-Novgoroder Angebot an Pelzen und Wachs, zum zweiten durch das westeuropäische Interesse an diesen Produkten, die im Tausch für westliche Luxuswaren eingehandelt werden sollten, und zum dritten durch den durch die Christianisierung hervorgerufenen Bedarf an haltbaren Fischen als Fastenspeise, in diesem Falle an Ostseehering, der vor allem gegen Salzlieferungen eingetauscht wurde, ${ }^{7}$ ein Handel, der die Verbreitung des Lüneburger Salzes im Ostseeraum zu Lasten des Kolberger Salzes beschleunigt haben wird. Auch wenn alle drei Faktoren als Konstante den Handel bis ins 16. Jahrhundert bestimmt haben, so geschahen im 12. Jahrhundert wesentliche Veränderungen, die die Entwicklung maßgeblich beeinflussten.

Der russische Pelzhandel des ausgehenden 11. und beginnenden 12. Jahrhunderts war großen Umwandlungsprozessen unterworfen. Bestimmten vorher russische Exporte nach Bulgarien und vor allem nach Byzanz das Bild, so versiegte dieser Exportzweig fast vollständig. Als Folge dessen konzentrierte sich der Pelzexport jetzt vor allem im Novgoroder Gebiet, das seine Handelswege explizit auf den Handel mit dem Westen ausrichtete. ${ }^{8} \mathrm{Zu}$ Anfang waren die Gutnen ${ }^{9}$, Schweden und Norweger und

\footnotetext{
${ }^{6}$ Siehe mit ähnlichem Gedankengang, allerdings den Forschungsstand des Jahres 2003 repräsentierend, Carsten JAHNKE und Anton ENGLERT, The state of historical research on merchant seafaring in Danish waters and in the Western Baltic Sea 1000-1250, in: Anton ENGLERT et al. (in Vorbereitung), Large Cargo Ships in Danish Waters 1000-1250. Evidence of professional merchant seafaring prior to the Hanseatic Period (Ships and Boats of the North, Vol. NN), Roskilde 2009 (im Druck).

${ }^{7}$ UBStL I, Nr. 27, S. 32f. Item de navi seu magna seu parva, sive de travena sive schania multociens dictorum burgensium [Lubicensis] ad partes nostras apllicantivm et labernas non facientivm, sed allec educentivm, datur punt salis ad thelonivm.

${ }^{8}$ Jane MARTIN, Treasure of the Land of darkness. The fur trade and its significance for medieval Russia, Cambridge 1986. S. 43-49. Christian RADTKE, Schleswig im vorlübischen Geld- und Warenverkehr zwischen westlichem Kontinent und Ostseeraum, in: Haithabu und die frühe Stadtentwicklung im nördlichen Europa, hg. von K. Brandt. M. Müller-Wille und Chr. Radtke, (Schriften des archäologischen Landesmuseums, Bd. 8), Neumünster 2002, S. 379-429. hier S. 384.

${ }^{9} \mathrm{Im}$ Anschluss an Detlef KatTinger, Die Gotländische Genossenschaft, Der frühhan-
} 
u. U. die Engländer die natürlichen Handelspartner der Novgoroder Kaufleute, die bis ins 13. Jahrhundert zum Beispiel englische Stoffe und Münzen nach Novgorod importierten, ${ }^{10}$ doch änderte sich das Bild langsam seit dem Beginn des 12. Jahrhunderts, als Novgoroder Kaufleute begannen, auch direkt mit westfälischen und sächsischen" Kaufleuten Handel zu treiben. ${ }^{12}$

Kontaktpunkte des Handels fanden sich sowohl an der Ost- wie auch an der Westküste des Ostseeraumes. Im Osten entwickelte sich die Stadt Novgorod zu einem Zentrum des Pelz- und Wachshandels, besonders gut ablesbar an der Einrichtung des skandinavischen St. Olavhofes in der Stadt, der spätestens zur Mitte des 12 . Jahrhunderts existierte. ${ }^{13}$ Weiterhin reisten Novgoroder Kaufleute aber auch gen Westen, wo sie zum einen auf Gotland Handel trieben, aber auch bis zur Westküste vordrangen. Für das Jahr 1130 berichtet die älteste Novgoroder Chronik über die wohlbehaltene

sisch-gotländische Handel in Nord- und Westeuropa (QDhG, N.F.. 47), Köln. Weimar. Wien 1999, S. 6 und passim, werden die Bewohner der Insel Gotland in diesem Beitrag als Gutnen bezeichnet.

${ }^{10}$ Karl Leopold GoETz, Deutsch-Russische Handelsbeziehungen des Mittelalters, Lübeck 1922, QDhG. N.F., 5, S. 35-36; A. L. CHOROsCHKIEWITSCH (Choroskevitš), Nowgorodischwarägische Bezichungen der ersten Hälfte des 11 . Jahrhunderts nach Angaben von russischen Urkunden, in: Julia-K. Büthe, Thomas Riis (Hg.), Studien zur Geschichte des Ostseeraumes. Vol. III. Stadtwerdung und städtische Typologie des Ostseegebietes bis zur Mitte des 18. Jahrhunderts. Odense 1999 (Odense University Studies in History and Social Scienses, 204), S. 26-33, hier S. 31: Dick WASE. Die früheste deutsche Ansiedlung auf dem ,gotischen Ufer" in Visby, in HGbll. 118, 2000, S. 9-33, hier S. 11. Elena A. RYBINA, Frühe "Jointventures«. Die Beziehungen Novgorods im Ostseeraum, in: Novgorod. Das mittelalterliche Zentrum und sein Umland im Norden Rußlands, hg. von Michael Müller-Wille. Valentin L. Janin. Evgenij N. Nosov und Elena A. Rybina, Neumünster 2001. Studien zur Siedlungsgeschichte und Archäologie der Ostseegebiete, Bd. I, S. 29l-308, vor allem S. 293-297. Die Frage nach der Herkunft der für russische und estnische Hortfunde dieser Zeit typischen hohen Anzahl englischer und friesischer Münzen ist umstritten. Vertritt Chr. RaDTKE, Schleswig im vorlübischen Geld- und Warenverkehr (wie Anm. 8) die Auffassung, dass dieses nicht auf einen direkten Handelskontakt hindeutet (op. cit. S. 380), so vertreten estnische Historiker und Numismatiker die gegenteilige Meinung. Siehe u.a. Ivar LEIMUS, Der Münzfund von Arkna (Arkanal) und die friesischen Pfennige in den Münzschätzen des Ostseeraumes im dritten Viertel des 11. Jahrhunderts, in: Töid Ajaloo Alalt, Bd. II, Tallinn 2000, S. 41-87, hier S. 5I-55. Siehe generell auch Bernd KLUGE, Das angelsächsische Element in den slawischen Münzfunden des 10. bis 12. Jahrhunderts. Aspekte einer Analyse, in: VikingAge Coinage in the Northern Lands. The sixths Oxford Symposium on Coinage and Monetary History, Part I, hg. von M.A.S. Blackburn und D.M. Metcalf (BAR, International Series 122 [I]), Oxford 1981, S. 257-327, hier S. 285-291.

"Aksel E. ChristenSEN. Scandinavia and the Advance of the Hanseatics, SEHR 5, 1957, S. 89-117, hier S. 98. Carsten MülLER-BOYSEN, Kaufmannsschutz und Handelsrecht im frühmittelalterlichen Nordeuropa, Neumünster 1990, S. 47. Alfons DOPSCH, Die Wirtschaftsentwicklung der Karolingerzeit, vornehmlich in Deutschland, Vol. 1-2, Weimar ${ }^{2}$ 1913-1921, II, S. 195.

12 MARTin, Treasure (wie Anm. 8), S. 48-52.

${ }^{13}$ MARTIN, Treasure (wie Anm. 8), S. 50 mit Hinweis auf die russisch-archäologische Literatur. 
Rückkehr russischer Kaufleute aus Dänemark, ${ }^{14}$ wohingegen 1134 russische Kaufleute in Dänemark überfallen wurden, ${ }^{15}$ was sie aber nicht davon abhielt, weiterhin nach Dänemark zu fahren, wo sie 1142 vor der schwedischen Küste ${ }^{16}$ und im Winter 1156/57 in Schleswig erneut ausgeraubt wurden. ${ }^{17}$ Auch die Heirat zwischen dem schleswigschen Jarl Knut Lavard und der Novgoroder Fürstentochter Ingeborg lässt auf die engen Beziehungen zwischen Schleswig und Novgorod schließen. ${ }^{18}$ Erst am Ende des 12. Jahrhunderts finden sich sowohl in den russischen als auch in den westlichen Quellen keine russischen Handelsflotten im westlichen Ostseeraum mehr. ${ }^{19}$

Einer der wichtigen Kontaktpunkte des Handels mit Novgorod war, wie schon bei Saxo ersichtlich, die Stadt Schleswig, die, wie die Ausgrabungen der letzten Jahre gezeigt haben, seit dem Ende des 11. Jahrhunderts einen besonderen ökonomischen Aufschwung erlebte. Schleswig nahm am Ausgang des 11. wie im 12. Jahrhundert eine besondere Schlüsselstellung bei der Verknüpfung der Wirtschaftssysteme des Deutschen Reiches, Dänemarks und vor allem aber auch des östlichen Ostseeraumes ein..$^{20}$ Schleswig war Umschlagplatz für das vor allem im Osthandel benötigte Silber, ${ }^{21}$ Konversionsplatz zwischen dem westlichen Münzgeld- und der im Ostseeraum praktizierten Gewichtsgeldwirtschaft, ${ }^{22}$ vor allem aber Schnittstelle zwischen dem west-östlichen Pelz/Wachs-Tuch- und Luxushandel. ${ }^{23}$ Die Bedeutung dieser Stadt lässt sich in vielfacher Weise beschreiben, wird aber am deutlichsten, wenn man den im 11. Jahrhundert

${ }^{14}$ Die erste Novgoroder Chronik nach ihrer ältesten Redaktion, 1016-1333/1352, in deutscher Übersetzung, hg. von J. DiETzE, Leipzig (München) 1971, S. 57.

${ }^{15}$ Novgoroder Chronik (wie Anm. 14), S. 58.

${ }^{16}$ MARTIN, Treasure (wie Anm. 8), S. 50.

${ }^{17}$ Saxo Grammaticus, Gesta Danorum. Danmarkshistorien, hg. von Karsten Friis-Jensen und Peter Zeeberg, II Bde., København 2005, Buch 14, Cap. 17,1, II, S. $214 \mathrm{f}$.

${ }^{18}$ Walther LAMMERS, Das Hochmittelalter bis zur Schlacht bei Bornhöved, Neumünster 1981. Geschichte Schleswig-Holsteins, Vol. 4,1, S. 255. John LiND, De russiske ægteskaber. Dynasti- og alliancepolitik i 1130'ernes danske borgerkrig ([dansk] HT, 16.I, Bd. 92), 1992, S. 225-261, hier S. 228-235.

${ }^{19}$ Norbert ANGERMANN, Novgorod und seine Beziehungen zur Hanse. in: Wilfried Westermann (ed.), Europas Städte zwischen Zwang und Freiheit, Regensburg 1995, S. 189-202. hier S. 198.

${ }^{20}$ Siehe zuletzt Christian RADTKE, Schleswig ca. 1000-1250. Systemtheoretische Skizzen eines Urbanisierungsprozesses, in: Zweiundvierzig, Festschrift für Michael Gebühr, hg. von Stefan Burmester, Heidrun Derks und Jasper von Richthofen, Rahden in Westfalen 2007, S. 317-338.

${ }^{21}$ MARTIN, Treasure (wie Anm. 8), S. 51.

22 RADTKE. Schleswig (wie Anm. 20), 321 f., sowie jetzt Rolf HAMMEL-KIESOW, Determinanten des Handels zwischen dem Ostseeraum und Niederdeutschland vom 10. bis zum 13./14. Jahrhundert, in: Jürgen Sarnowsky, Burghart Schmidt (Hg.): Die Kontinuität der hansischen Dimension im baltischen Raum, Hamburg im Druck für 2008/09.

${ }^{23}$ RADTKE, Schleswig im vorlübischen Geldverkehr (wie Anm. 8), S. $408 \mathrm{ff}$. und $41 \mathrm{lff}$. 
nach modernsten Standards ausgebauten und erweiterten Hafen betrachtet. $^{24}$

Hier an der Schlei trafen die Novgoroder und die skandinavischen Kaufleute auf westeuropäische Handelspartner. ${ }^{25}$ Der wichtigste Beleg für den eingespielten Handel der deutschen Kaufleute mit dem Osten findet sich dabei in den Rechtssätzen der kleinen sauerländischen Stadt Medebach, die 1165 das Soester Recht verliehen bekam, welches nach Vorarbeiten seit 1144 aus diesem Anlass zum ersten Mal aufgezeichnet wurde. ${ }^{26}$ Der Artikel 15 lautet:

Qui pecuniam suam dat alcui concivi suo, ut inde negocietur in Datia vel Rucia vel in alia regione ad utilitatem utriusque, assumere debet concives suos fideles, ut videant et sint testes huius rei. ${ }^{27}$

„Wenn jemand sein Geld einem Mitbürger mitgibt, dass dieser in Dänemark oder in Russland oder in anderen Regionen damit zu beiderseitigem Nutzen Handel treibt, so ist er verpflichtet, verläßliche Mitbürger herbeizuziehen, damit sie dieses sehen und bezeugen können“".

Aus diesen und den folgenden Ausführungen wird deutlich, dass die Medebacher und Soester Kaufleute zu diesem Zeitpunkt regelmäßige Handelsreisen in den Ostseeraum unternahmen, die so organisiert waren, dass einzelne Kaufleute persönlich nach Osten reisten und dabei Waren resp. Geld ihrer heimischen Partner mitnahmen, über deren Erlös nach Beendigung der Reise wieder in der Heimat abgerechnet wurde. ${ }^{28}$ Dass unter „Datia“ wahrscheinlich Schleswig zu verstehen ist, ergibt sich daraus, dass sich die reichsten Bürger Soests noch in späterer Zeit „Schleswigfahrer“ nannten und damit auf den Ursprung ihres Reichtums im Handel mit Südweinen in den Norden rekurrierten. ${ }^{29}$ Gleichfalls können die Kölner „Dänemarkfahrer" des 12. Jahrhunderts als Schleswigfahrer identifiziert werden ${ }^{30}$ und für die Zeit um 1131/1134 kann ein starker Kölner Einfluss in

${ }^{24}$ Volker VoGEL, Der Schleswiger Hafen im hohen und späten Mittelalter, in: Maritime Topography and the Medieval Town. Papers from the 5th international conference on waterfront archaeology in Copenhagen, 14-16 may 1998 (Publications from The National Museum. Studies in Archaeology \& History, Vol. 4). Copenhagen 1999, S. 187-196.

${ }^{25}$ Siche hierzu ausführlich Hammel-KiEsow. Determinanten (wie Anm. 22), im Druck.

${ }^{26}$ Albrecht CORDES. Spätmittelalterlicher Gesellschaftshandel im Hanseraum (QDhG. N.F.. 45) Köln. Weimar, Wien 1998, S. 58f.

${ }^{27}$ Nach CoRdes, Gesellschaftshandel (wie Anmr. 26), S. 58. Dipl. Dan. I.2., Nr. 166. S. 312 .

${ }^{28}$ CORDES, Gesellschaftshandel (wie Anm. 26), S. $61 \mathrm{f}$.

29) LAMMERS, Hochmittelalter (wie Anm. 18), S. 255; Christian RADTKE, Schleswig und Soest, Einige Beobachtungen aus Schleswiger Sicht. SoesterZs. 93/93, 1981. S. 433-478. Zugleich: Soest, Stadt - Territorium - Reich, Festschrift zum 100jährigen Bestehen des Vereins für Geschichte und Heimatpflege Soest. Hier S. $444 \mathrm{f}$.

${ }^{30}$ Christian RadTKE, Die Entwicklung der Stadt Schleswig: Funktionen, Strukturen und die Anfänge der Gemeindebildung. In: Erich Hoffmann, Frank Lubowitz (Hg.). Die Stadt im 
der Stadt Schleswig nachgewiesen werden, der sich nur durch intensive Fernhandelsbeziehungen erklären lässt. ${ }^{31} \mathrm{Ob}$ allerdings eine nur sekundär überlieferte Urkunde für Neuß $\beta^{32}$ Erik Emune zugeordnet werden kann, wie Christian Radtke es vorschlägt ${ }^{33}$, bleibt angesichts der Quellenlage fraglich.

Im 12. Jahrhundert erreichte der Transitweg Hollingstedt-Schleswig seine höchste Blüte, was ebenfalls als ein Indiz für den regen Ost-Westhandel gedeutet werden kann. Dieses wird zum einen durch die Verwendung rheinischen Tuffs beim Bau der Ripener und Schleswiger Dome und anderer Kirchen in der Umgebung Ripens und Schleswigs sichtbar, wobei die entsprechenden Abschnitte des Dombaues auf die Zeit 1120 bis 1160 gesetzt werden. ${ }^{34}$ Weiterhin deutet ein St. Martin Patrozinium in Schleswig auf die Anwesenheit rheinischer Kaufleute in der Stadt, was sich auch in den Marktterminen niederschlug. ${ }^{35}$ Insgesamt kann für das gesamte 12. Jahrhundert von einer engen wirtschaftlichen Verbundenheit des Rheinlandes und Westfalens mit Schleswig und über Schleswig mit dem Ostseehandel gesprochen werden. ${ }^{36}$

Aber nicht nur westeuropäische Kaufleute übernahmen an der Schlei die Novgoroder Handelswaren, auch Schleswiger und andere dänische Kaufleute betrieben den aktiven Westhandel. So lassen sich schon seit dem 11. Jahrhundert verstärkte Handelsverbindungen zu den britischen Inseln feststellen, wo zum Beispiel die Dänen in London schon um 1040 eine Kirche errichteten. ${ }^{37}$ Um 1120 handelten Schleswiger Fernhändler regelmäßig mit Zobelfellen im Rhônedelta, ${ }^{38}$ wie sich auch Ripener und däni-

westlichen Ostseeraum, Vorträge zur Stadtgründung im Hohen Mittelalter. Vol. I (Kieler Werkstücke. Reihe A. Band 14), Frankfurt am Main. Berlin, Bern 1995. S. 47-91. hier S. 61.

${ }^{31}$ RADTKE, Entwicklung (wie Anm. 30), S. $78 \mathrm{ff}$.

${ }^{32}$ Dipl. Dan. II.12, S. 217.

${ }^{33}$ RADTKE, Entwicklung (wie Anm. 30). S. 61, Ders., Schleswig und Soest (wie Anm. 29), S. $449 \mathrm{ff}$.

${ }^{34}$ Dietrich Ellger. Der Dom und der ehemalige Dombezirk (Die Kunstdenkmäler des Landes Schleswig-Holstein. Die Kunstdenkmäler der Stadt Schleswig, II), sine loco 1966. S. 192-195. Jan Bill. Bjørn Poulsen, Flemming RieCK und Ole Ventegodt, Dansk Søfarts Historie. Bd. I, Fra stammebåd til skib, København 1997, S. 145.

${ }^{35}$ KatTinger, Gotländische Genossenschaft (wie Anm. 9), S. 20f.; RadTKE, Schleswig und Soest (wic Anm. 29), S. 455.

${ }^{36}$ RADTKE. Schleswig und Soest (wie Anm. 29), S. 44 Iff.

${ }^{37}$ Alexander BugGE. Die nordeuropäischen Verkehrswege im frühen Mittelalter und die Bedeutung der Wikinger für die Entwicklung des europäischen Handels und der curopäischen Seefahrt, in: VSWG 4, 19(06, S. 227-277, hier S. 26/f.; Bul.l. et al., Søfarts Historie (wie Anm. 34), S. 138f.

${ }^{38}$ Miracula Beati Egidii, MGH SS in Folio, Vol. XII, Historia aevi Salici, hg. von Georg Heinrich PerTZ. Hannover 1856. S. 316-323, hier S. 320. Erwin AssmanN, SchleswigHaithabu und Südwesteuropa. ZGesSHG 78. 1954. S. 284-288. Hektor AmMANN, Die Deutschen in Saint-Gilles im 12. Jahrhundert. In: Festschrift für Hermann Aubin zum 80. Ge- 
sche (und damit wahrscheinlich Schleswiger) Kaufleute im Westen in den Jahren bis 1227 und darüber hinaus ungebrochen wieder fïnden lassen. So halten sich Ripener beziehungsweise dänische Kaufleute in England auf ${ }^{39}$ und 1224 werden die Dänen im Englandhandel mit den Schotten, Friesen, Isländern und Kölnern gleichgestellt. ${ }^{40}$

Schleswig war bis zur Mitte des 12. Jahrhunderts und darüber hinaus eines der bedeutendsten Wirtschaftszentren des dänischen Reiches und die geographisch natürliche Verknüpfung des Ost- und Westhandels, selbst wenn der dänische Bürgerkrieg bis zur Mitte des Jahrhunderts den Handel dieser Stadt sicherlich erschwert haben wird. Unterstrichen wird die Bedeutung der Stadt weiterhin dadurch, dass das Königtum dort eine der wenigen Reichspfalzen errichten und im Laufe des 12. Jahrhunderts ausbauen ließ.

Den Handel im Ostseeraum allerdings nur auf die Route NovgorodSchleswig zu konzentrieren wäre zu kurz gedacht. So betrieben zum Beispiel die Gutnen einen lebhaften Handel mit Ostwaren zwischen Novgorod, ihrer Insel und England, waren aber auch im Schleswighandel und im Handel mit Norwegen präsent. ${ }^{4 \mid}$ Ihre besonders wichtige Stellung ist sowohl archäologisch wie auch historisch ausreichend belegt und soll an dieser Stelle nicht weiter ausgeführt werden..$^{42}$ Ebenfalls ist auf die Friesen hinzuweisen, ${ }^{43}$ die an diesem Handel teilnahmen, auf slawische Kaufleute, deren Rolle bis heute noch weitgehend ungeklärt ist, ${ }^{44}$ und auf andere Kaufleutegruppen, die das quellenmäßige Bild bereichern. ${ }^{45}$ Ebenfalls lief der Handel natürlich nicht nur auf der Ost-Westroute, sondern umfasste

burtstag, hg. von Otto Brunner, Hermann Kellenbenz, Erich Maschke, Wolfgang Zorn, Vol. I-II, Wiesbaden 1965, I, S. 185-220. RADTKE, Schleswig und Soest (wie Anm. 29), S. 438. Waren des Ostseeraums finden sich nicht nur auf den Messen von Saint-Gilles, sondern auch auf den Messen der Champagne und in den anderen wichtigen südeuropäischen Messeorten, vgl. einleitend Michel PAULY, Der Beitrag der Messen und Märkte zur mittelalterlichen Integration Europas, in: Messen, Jahrmärkte und Stadtentwicklung in Europa, Foires, marchés annuels et développement urbain en Europe, hg. von Franz Irsigler und Michel Pauly, Trier 2007, S. 285-314, hier besonders S. 293 und 298. Die Warenströme aus dem Ostseeraum auf die Champagnemessen sind bisher noch nicht umfassend untersucht.

${ }^{39}$ Dipl. Dan. I.4, Nr. 144, S. 268f. und I.6, Nr. 20, S. 40; I.6, Nr. 21, S. 40 und Nr. 61 , S. 80. BILl et al, Søfarts Historie (wie Anm. 34), S. $139 \mathrm{f}$.

40 Dipl. Dan. I.6, Nr. 24, S. 43.

"KATTINGER, Gotländische Genossenschaft (wie Anm. 9), S. $233 \mathrm{f}$.

$12 \mathrm{Vgl}$. mit einer umfangreichen Literaturübersicht KATTINGER, Gotländische Genossenschaft (wie Anm 9), S. 27, Note 135; WASE, Ansiedlung (wie Anm. 10).

${ }^{\$ 3}$ RADTKE, Schleswig im vorlübischen Geldverkehr (wie Anm. 8), S. $390 \mathrm{ff}$.

t4 Siehe einleitend die Hinweise bei RADTKE, Schleswig im vorlübischen Geldverkehr (wie Anm. 8), S. 395 und HAMMEL-KIESOw, Determinanten (wie Anm. 22), im Druck.

${ }^{45} \mathrm{Zu}$ den Problemen des Handels zwischen christlichen und paganen Kaufleuten aus kirchlicher Sicht siehe Rasa MAŽEIKA, Of cabbages and knights: trade and trade treaties with the infidel on the northern frontier, 1200-1390, in: JMH 20, 1994, S. 63-76, hier S. 65ff. 
viele bedeutende und weniger bedeutende Zwischenstationen, von denen die frühstädtischen urbanen Zentren im südlichen Ostseeraum nur einige sind. ${ }^{46}$

Alle Handelsgruppen zusammen bildeten spätestens seit dem beginnenden 12. Jahrhundert ein funktionierendes und eingespieltes Handelssystem bei dem der Novgoroder Markt mit Silber, Tuch und Luxuswaren versorgt wurde und der Westen das für die Altäre benötigte Wachs und die so prestigeträchtigen Pelze erhielt.

Eine zusätzliche und etwas anders geartete Komponente erhielt der Handel im Ostseeraum durch die fortschreitende Christianisierung Mittelund Osteuropas und das wirtschaftliche Aufblühen vor allem der binnenländischen westfälischen und sächsischen Städte. Deren Handel lag rein geographisch etwas abseits von dem großen Schleswiger Handelsstrom und die Kaufleute dieser Städte mussten versuchen, andere Wege zu finden, um an Ostwaren zu gelangen. Gleichzeitig hatte die Festigung der christlichen Fastengebote in diesen Gebieten zu einer verstärkten Nachfrage nach fastentauglichen Fischen, d.h. vor allem nach Hering, geführt. ${ }^{47}$ Dieses ließ die Kaufleute auf den Ostseeraum schauen und verstärkte den Handel mit den nicht-christianisierten Landschaften, vor allem mit den slawischen Ruganern; ${ }^{48}$ so berichtete schon 1124 Otto von Bamberg begeistert über den Heringsreichtum Rügens ${ }^{49}$ und versuchte 1147 das Kloster Corvey sich die heidnische Insel durch eine Fälschung anzueignen. ${ }^{50}$

Hauptknotenpunkt dieses Handels war der alte karolingische Grenzort Bardowick, der vor allem davon profitieren konnte, dass er auf dem Wege zwischen den Salzquellen von Lüneburg und dem Meer lag. ${ }^{51}$ Bardowick stellte den letzten ,deutschen" Handelspunkt vor dem Slawenland dar, und hier an der wichtigsten Süd-Nordverbindung lag ebenfalls eine bedeutende kaiserliche Zollstelle, wie aus einem Privileg Kaiser Lothars III. für das

\footnotetext{
${ }^{46}$ Siehe hierzu einleitend Ole CrUMLIN-PEDERSEN, Schiffahrt im frühen Mittelalter und die Herausbildung früher Städte im westlichen Ostseeraum, in: Haithabu und die frühe Stadtentwicklung (wie Anm. 8), S. 67-81.

${ }^{47}$ Carsten JAHNKE, Wege und Absatzmärkte im Handel mit Ostseehering, 1100-1600. Kontinuität und Wandel, in: Der Ostseeraum und Kontinentaleuropa, 1100-1600, Einflussnahme-Rezeption-Wandel, hg. von Detlef Kattinger, Jens E. Olesen und Horst Wernicke, Schwerin 2004, S. 131-136.

${ }^{48}$ Siehe hierzu einleitend Lech LECIEJEWICZ, Zum frühmittelalterlichen Heringshandel im südlichen Ostseegebiet, in: ZArchäol. 25, 1991, 2, S. 209-214.

${ }^{49}$ Herbordi, Dialogus de Vita Ottonis, MGH SS rer. Germ., Vol. 33, hg. von Georg Heinrich PERTZ, Hannover 1868, II:41, S. 102.

51) JAHNKE, Wege (wie Anm. 47), S. 131.

5I Arnold KiESSELBACH, Die wirtschaftlichen Grundlagen der deutschen Hanse und die Handelsstellung Hamburgs bis in die zweite Hälfte des 14. Jahrhunderts, Berlin 1907, S. $10 \mathrm{f}$. Torsten KEMPKE. Bemerkungen zur Delvenau-Stecknitz-Route im frühen Mittelalter, in: Hammaburg, NF 9, 1989, Festschrift für Wolfgang Hübner, S. 175-184, hier S. 175-180.
} 
Kloster Quedlinburg deutlich wird. ${ }^{52}$ Es ist davon auszugehen, dass es vor allem sächsische und westfälisch-binnenländische Kaufleute waren, die diesen Handelsweg genutzt haben. ${ }^{53}$

Folgt man von Bardowick aus dem günstigsten Weg nach Norden, so trifft man bei Artlenburg auf die erste passierbare Furt über die Elbe, von wo aus der schnellste und kürzeste Weg zum Meer in Richtung Trave, d.h. nach Lübeck führt. ${ }^{54}$ Die schon im 11. Jahrhundert existierende Kaufmannssiedlung in Alt-Lübeck rückt 1127 in das historische Blickfeld, als Vicelin Missionare in die dortige Burg schickt, die receptique sunt benigne a mercatoribus, quorum non parvam coloniam Henrici principis fides et pietas ibidem consciverat, „von den Kaufleuten, deren ansehnliche Niederlassung der redliche und gerechte Fürst Heinrich dorthin zusammengeholt hatte, freundlich empfangen wurden". ${ }^{55}$ Die freundliche Aufnahme der Missionare und der baldige Bau einer Kirche an diesem Ort deuten darauf hin, dass sich dort Kaufleute verschiedenster Nationen zusammengefunden hatten, unter denen sich einige Christen befunden haben müssen. Rolf Hammel-Kiesow vermutet, dass es sich wahrscheinlich um deutsche, nordische und möglicherweise christianisierte slawische Kaufleute gehandelt hat. ${ }^{56}$ Ein weiterer Hinweis auf die zunehmende Bedeutung des Traveortes könnte die Erwähnung des Namens leybica auf einem gotländischen Runenstein aus der Zeit um 1100 sein. ${ }^{57}$

Alt-Lübeck hatte eine geographisch besonders günstige Lage im Handel zwischen Sachsen und dem Ostseeraum. Dieser Handel wurde 1134 durch Kaiser Lothar von Süpplingenburg durch ein Privileg auf eine rechtlich gesicherte Grundlage gestellt. Dieses Privileg ist im Original nicht mehr erhalten, kann aber durch die Untersuchungen Detlef Kattingers zum Teil erschlossen werden. ${ }^{58}$ Das Privileg von 1134 erfolgte zu einem Zeitpunkt, als Schleswig und Dänemark in interne Thronkämpfe verwickelt waren und die Stadt selbst einer mehrjährigen Belagerung widerstehen musste. In

${ }^{52} \mathrm{MGH}$, DD, Dipl. reg. imp. Germ., Lothar III, hg. von Emil von OTTENTHAL, Berlin 1927, Nr. 61, S. 65 ff., hier S. 66.

${ }^{5.3}$ Allerdings zieht KEMPKE, Bemerkungen (wie Anm. 51), S. 180, das Fazit, dass, obwohl die Funde auf den Handel schließen lassen, sie von der Menge her gesehen nicht sonderlich beeindruckend seien.

${ }^{54}$ Rolf HAMMEL-KIESOW, Lübeck. Frühe Stadtgeschichte und Archäologie. Kritische Betrachtungen aus der Sicht eines Historikers, in: ZVLGA 64, 1984, S. 9-38, hier 15.

${ }^{55}$ Helmoldi Presbyter Bozoviensis Chronica Slavorum, MGH SS rer. Germ, Bd. 32, hg. von Bernhard SCHMEIDlER. Hannover ${ }^{2}$ 1937, Cap. 48, S. 95. KATTINGER, Gotländische Genossenschaft (wie Anm. 9), S. 24.

${ }^{56}$ Rolf HAMMEL, Die Anfänge Lübecks, Von der abodritischen Landnahme bis zur Eingliederung in die Grafschaft Holstein-Stormarn, in: Antjekathrin Graßmann (Hg.), Lübeckische Geschichte, Lübeck ${ }^{4} 2008$, S. 30.

${ }^{57}$ KatTinger, Gotländische Genossenschaft (wie Anm 9), S. $25 \mathrm{f}$.

${ }^{58}$ RI IV 1, 1, Nr. d403. KATTINGER, Gotländische Genossenschaft (wie Anm 9), S. 37-46. 
dieser Situation förderte Lothar die sächsischen Städte, indem er den gutnischen Kaufleuten weit reichende Privilegien in den Bereichen der Rechtssicherheit und Friedenssicherung einräumte, die die grundsätzliche Basis für den Handel darstellten. ${ }^{59}$ Alt-Lübeck wird in dem Text nicht explizit erwähnt, ein Bezug auf die Stadt ist aber aus der späteren Entwicklung zu vermuten.

Die lübische Siedlung konnte aber kaum sofort von der neuen Rechtslage profitiert haben, denn sie wurde in die Auseinandersetzungen nach dem Tode Lothars 1137 verwickelt und wahrscheinlich 1138 durch Fürst Race zerstört. ${ }^{60} \mathrm{Ob}$ diese Zerstörung zu einem Kontinuitätsbruch in Lübeck führte, ist umstritten, bei der Betrachtung der weiteren Entwicklung aber unwahrscheinlich. ${ }^{\text {" }}$ Als gesichert kann aber gelten, dass die Zerstörung der Altsiedlung 1138 eine Neustrukturierung des Siedlungsraumes nach sich zog. Diese Siedlung wurde 1143 durch Graf Adolf I. von Holstein (Schauenburg) als Stadt ausgebaut, da der Graf sah, ,wie trefflich der Hafen war".62 Die Neusiedlung erhielt den slawischen Namen ihrer Vorgängerin, was ebenfalls als ein Indiz für die Etablierung dieses Ortes im internationalen Handel gewertet werden kann. ${ }^{63}$

Als Fazit dieser kurzen Skizze der Handelsverhältnisse des Ostseeraumes am Ausgang des 11. und am Beginn des 12. Jahrhunderts soll vor allem herausgestrichen werden, dass sich die Hauptachse des Transitverkehres zwischen Ost und West unter Beteiligung von Russen, Gutnen, Friesen, Slawen ${ }^{64}$ und Deutschen auf der Strecke Novgorod-Schleswig etabliert hatte. Parallel dazu trieben friesische, sächsische und westfälische Kaufleute über Bardowick Handel an der slawischen Küste, darunter auch

\footnotetext{
${ }^{59}$ KATTINGER, op.cit.

${ }^{60}$ Helmold. Chronica (wie Anm. 55), Cap. 55, S. $107 \mathrm{ff}$.

${ }^{61}$ Hammel, Anfänge (wie Anm. 56), S. 43; Erich HofFMAnN, Sachsen, Abodriten und Dänen im westlichen Ostseeraum von der Mitte des 10. bis zur Mitte des 12. Jahrhunderts, in: Helge bei der Wieden (Hg.), Schiffe und Seefahrt in der südlichen Ostsee (Mitteldeutsche Forschungen 91), Köln, Wien 1986, S. 1-40, hier S. 12.

${ }^{62}$ Helmold. Chronica (wie Anm. 55), Cap. 57, S. 11 Iff. Bernhard AM ENDE, Studien zur Verfassungsgeschichte Lübecks im 12. und 13. Jahrhundert (Veröffentlichungen zur Geschichte der Hansestadt Lübeck. Reihe B. Bd. 2, 1975), Lübeck 1975, S. $92 \mathrm{f}$.

${ }^{63}$ Rolf Hammel-Kiesow, Neue Aspekie zur Geschichte Lübecks: von der Jahrtausendwende bis zum Ende der Hansezeit. Die Lübecker Stadtgeschichtsforschung der letzten zehn Jahre (1988-1997). Teil 1: bis zum Ende des 13. Jahrhunderts, ZVLGA 78, 1998, S. 47-114. hier S. 61.

${ }^{n} \mathrm{Zu}$ den Slawen siehe einleitend Lech LECIEJEwICZ, Zur Entwicklung von Frühstädten an der südlichen Ostseeküste, in: ZArchäol. 3, 1969, S. 182-210, hier S. 190ff. DERS., Kaufleute in westslawischen Frühstädten in archäologischer Sicht, in: Burg-Burgstadt-Stadt, Zur Genese mittelalterlicher nichtagrarischer Zentren in Ostmitteleuropa, hg. von Hansjürgen Brachmann. Berlin 1995, S. 60-67.
} 
in Lübeck, das aufgrund seiner verkehrsgeographischen Situation von Süden aus gesehen besonders günstig lag. ${ }^{65}$

\section{Die „Gründung“ Lübecks und deren Bedeutung für den Handel im Ostseeraum}

In dieser Situation unternahm Graf Adolf von Holstein seine Anstrengungen, das slawische Wagrien durch deutsche Siedler zu kolonisieren und wirtschaftlich zu erschließen, um sich damit eine eigene Machtposition gegen den einheimischen Adel aufzubauen. Die folgenden Ereignisse im Zusammenhang mit Lübeck sind Legion und sollen an dieser Stelle nur summarisch abgehandelt werden. 1143 erhielt die Siedlung durch Adolf städtische Rechte. ${ }^{66}$ Die neue gräfliche Siedlung florierte so sehr, dass die Einnahmen des sächsischen Herzogs, vor allem in Bardowick, immer mehr zurückgingen, so dass es zu Auseinandersetzungen zwischen dem Grafen und seinem Lehnsherrn kam, die 1159 zum Übergang der Stadt an den sächsischen Herzog Heinrich den Löwen führten. ${ }^{67}$

Bei diesen Vorgängen sind vor allem zwei Dinge besonders festzuhalten. Zum ersten handelt es sich bei Lübeck nicht um eine Siedlung auf grüner Wiese, sondern nur um die Stadterhebung einer vorhandenen Kaufmannssiedlung mit internationalem Bekanntheitsgrad. ${ }^{68}$ Allein die Übernahme des alten, slawischen Namens Lubice deutet darauf hin, dass man das Ansehen der alten Handelssiedlung nutzen wollte. Zum zweiten war vor allem Bardowick von dem florierenden Handel in Lübeck betroffen. Das heißt, dass sich der ehemalige Grenzhandel nun direkt ans Meer verlagert hatte und - das zumindest kann man aus den zurückgehenden Zolleinnahmen des Herzogs schließen - dass sich der Salz- und Heringshandel nun Wege an Bardowick vorbei gesucht hatte. ${ }^{69}$ Die Vorgänge der Jahre bis 1159 lassen aber auf keinen Fall den Schluß zu, dass Lübeck die Rolle einer Vermittlerin zwischen Ost- und Nordsee zugedacht war. Dieses hätte zum einen Bardowick nicht betroffen und wäre zum anderen schon allein daran gescheitert, dass der Stadt ein Westhafen gefehlt hätte.

Die Ausrichtung des lübischen Handels ins südliche Binnenland lässt sich dabei archäologisch wie auch historisch relativ gut belegen. So zeigt

\footnotetext{
${ }^{65}$ Siehe allgemein Lech LECIEJEWICZ, Sachsen in den slawischen Ostseestädten im 10.-12. Jahrhundert, in: ZArchäol. 21, 1987, S. 75-81.

${ }^{6}$ Helmold, Chronica (wie Anm. 55), Cap. 57, S. $111 \mathrm{ff}$. AM ENDE, Verfassungsgeschichte (wie Anm. 62), S. 92f.

${ }^{67}$ Karl JORDAN, Heinrich der Löwe, München 1978, S. 80-83.

${ }^{68}$ HAMMEL-KIESOW, Lübeck. Betrachtungen (wie Anm. 54), S. $16 \mathrm{f}$.

${ }^{69} \mathrm{Zu}$ diesen Handelsgütern Bardowicks siehe KJESSELBACH, Wirtschaftliche Grundlagen (wie Anm. 51), S. 10, Note 32.
} 
der Vergleich der Lübecker und Schleswiger Keramik, dass es „auch im 13. Jahrhundert noch eine Phase gegeben haben [muss], in der ein überregionaler Verkehr eher Schleswig als Lübeck erreichte ${ }^{6,}{ }^{70}$ ein Befund, der die Archäologen mehr als irritiert hat. Aber auch im Bereich der historischen Quellen ist dicsc Ausrichtung mehr als bekannt, wenn sie bisher auch weitgehend ignoriert wurde. So lässt sich die Stadt Lübeck von Kaiser Barbarossa 1188 mit der Zollfreiheit im ganzen Herzogtum Sachsen ausstatten. Allerdings hält sich der Kaiser eine detailliert ausgeführte Zollregelung vor: den Zoll am Artlenburger Elbübergang. Hierfür werden en detail die Zollbedingungen geschildert, vor allem auch für den Fall, dass die Handelskarren innerhalb von Jahr und Tag mehrmals die Burg passieren. ${ }^{7 l}$ Die Detailfülle der Regelung und ihr Ausnahmecharakter lassen den Schluß zu, dass 1188 der Weg nach Süden die Haupthandelsrichtung der Lübecker darstellte. ${ }^{72}$ Es ist höchst unwahrscheinlich, dass die Lübecker, die sicherlich maßgeblich an der Ausgestaltung des Privileges beteiligt waren, einen florierenden Handel mit Hamburg nicht explizit abgesichert hätten, einen Handel der zu diesem Zeitpunkt immer noch keinen sehr gut funktionierenden Gegenhafen gehabt hätte. ${ }^{73}$ wohingegen für eine sekundäre Handelsroute explizite Regelungen erlassen wurden, die eine geringere Bedeutung für die Lübecker Wirtschaft (und den kaiserlichen Zollverwalter) gehabt hätten. ${ }^{74}$ Vielmehr kann man getrost davon ausgehen, dass die Zollregelung von Artlenburg das Ergebnis harter Verhandlungen zwischen den städtischen Delegierten und dem Kaiser darstellte, das die Interessen beider Seiten berücksichtigte. Auch wenn es schon um diese Zeit Lübecker gegeben hat, die mit ihren Waren über Oldesloe nach Hamburg gezogen sind, ${ }^{75}$ so werden diese doch nicht das gros der lübischen Kaufmannschaft ausgemacht haben. Es kann daher konstatiert werden,

\footnotetext{
${ }^{70}$ Heinrich LUDTKE, Die mittelalterliche Keramik von Schleswig. Ausgrabung Schild 1971-1975, Neumünster 1985. Ausgrabungen in Schleswig, Bd. 4, S. 130.

${ }^{71}$ MGH, DD. Dipl. reg. imp. germ., Friderici I. Diplomata. Teil 4, 1181-1190, hg. von Heinrich APPELT, Hannover 1990, Nr. 981, S. 263-267, hier S. 265. Ad hec, ut cum mercibus suis libere erant et redeant per totum ducatum Saxonie absque hanse et absque theloneo preter Ertheneburch, ubi $V$ denarios de plaustro solvent, hoc addentes, quot plaustra illuc transduxerit, pro quibus theloneum supradictum dederint, si infra annum et diem redierint, tot plaustra libere sine theloneo reducent.

${ }^{72}$ Kiesselbach. Wirtschaftliche Grundlagen (wie Anm. 51), S. 21.

${ }^{73}$ Kiesselbach, Wirtschaftliche Grundlagen (wie Anm. 51), S. $17 \mathrm{ff}$.

${ }^{74}$ Zum historischen Hintergrund dieser Urkunde siehe Helmut G. WALTHER, Kaiser Friedrich Barbarossas Urkunde für Lübeck vom 19. September 1188, in: ZVLGA 69, 1989. S. $11-48$.

${ }^{75}$ Arnoldi, Chronika Slavorum, MGH, SS rer. Germ. in ususm scholarum 14, hg. von Johann Martin LAPPENBERG, Hannover 1868. III, 20, S. 109f. Siehe auch Gertrud SCHRECKER, Das spätmittelalterliche Straßennetz in Holstein und Lauenburg. I, ZGesSHG 61, 1933, S. 16-109, hier S. 26, die weitere Belege für das Jahr 1175 anführt.
} 
dass Lübecks Aufgabe bis zum Ende des 12. Jahrhunderts vornehmlich im Nord-Südtransfer und vor allem im Handel mit Hering und Salz bestand.

Welche Auswirkungen hatte nun die Gründung der Travestadt für den Handel im Ostseeraum? Nun, auf den ersten Blick und in den ersten Jahren keine. Graf Adolf und später auch Herzog Heinrich der Löwe schufen zuerst einmal vor allem die rechtlichen Voraussetzungen für einen florierenden Handel, was durch die Einrichtung einer Münze und des Marktes flankiert wurde. ${ }^{76}$ Betrachtet man Stadtgründungen in diesem Zeitraum vor allem unter rechtlichen Aspekten so ist aufmerksam eine Definition zu verfolgen, die zwischen 1225 und 1226 Prinz Heinrich Borwin von Rostock bei der Gründung der Stadt Parchim anführt:

Jtem datum est omnibus in terra morantibus, quod nullum ad concilium, quod marcdinc uocatur, sunt compellendi; similiter ad ius feodale, quod lenrecht uocatur, sunt minime conpellendi, sed tantum ad ius, [quod] mannerecht vulgo sonat. ${ }^{77}$

„Weiterhin soll allen Einwohnern des Landes [Parchim] eingeräumt sein, daß niemand länger dem Gericht unterstellt ist, welches Markding genannt wird, noch jemand unter das Lehnsrecht fällt, welches lenrecht genannt wird, sondern alle dem Gericht unterstehen, welches Mannrecht genannt wird".

Die neuen Bürger der Stadt Parchim (und damit aller Städte) werden erst einmal aus dem bisherigen Rechtsverband ausgegliedert, und zwar sowohl aus dem slawischen Landrecht, dem Markding, als auch aus dem Lehnsrecht. ${ }^{7 k}$ Das ist insofern von überaus großer Bedeutung, als hiermit die Bürger, und damit auch die Kaufleute, einer besonderen, ihren Bedürfnissen angepassten Rechtssprechung unterworfen und von den alten Fesseln befreit wurden. Die Bedeutung dieses Vorganges ist für die Freiheit des Handels von kaum zu überschätzender Wichtigkeit, wie Gerhard Dilcher gezeigt hat. ${ }^{79}$ Aber auch auf einen anderen Punkt ist explizit hinzuweisen: die ausdrückliche Erwähnung des ius feodale weist mehr als deutlich auf die Herkunft der Bürger in diesen Neugründungen und deren

${ }^{7 n}$ Zur Bedeutung des Duos Münze-Markt siehe Stuart JENKS, Die Welfen, Lübeck und die werdende Hanse, in: Die Welfen und ihr Braunschweiger Hof im hohen Mittelalter. hg. von Bernd Schneidtmüller (Wolfenbütteler Mittelalter Studien. Bd. 7), Wiesbaden 1995, S. 483-522, hier S. 488f.

${ }^{77}$ MUB I, Nr. 319. pp. 311f. Karl Augustin, Geschichte der Stadt Parchim, Parchim 1926, S. 6 f.

${ }^{78}$ Siehe Carsten JAHNKE. The influence of the Hanseatic League on the cities in the North-Sea and Baltic-Sea Area. Some reflections on the triad "trade - cities - Hanseatic League", im Druck.

${ }^{79}$ Gerhard Dilcher, Die Rechtsgeschichte der Stadt, in: Karl S. Bader und Ders., Deutsche Rechtsgeschichte, Land und Stadt - Bürger und Bauer im Alten Europa. Berlin, New York 1999. S. 251-828, hier vor allem $347 \mathrm{ff}$. 
Verknüpfung mit der Ministerialität hin. ${ }^{80}$ Dieses Zusammenspiel von Ministerialität und Kaufmannschaft in Norddeutschland um 1200 erklärt nun wiederum, wie die Forschungen von Enno Bünz ${ }^{81}$ und Hans Trüper ${ }^{82}$ zeigen, woher der plötzliche Kapitalzustrom stammte, der alle „neuen“ Städte im Ostseeraum auszeichnete. Graf Adolf ließ dic wagrischen Gebiete nicht nur teilweise durch Ministeriale aufsiedeln, er ermöglichte es vor allem auch, dass diese ihr Kapital in den Handel seiner neuen Stadt Lübeck investieren konnten und der Handel somit neue Dimensionen erreichen konnte. ${ }^{83}$ So konnte Hans G. Trüper am Beispiel Bremens zeigen. dass einige der (ritterbürtigen) Bürger der Stadt Bremen um 1200 nicht nur über Hausbesitz in der Stadt, sondern auch über ausgedehnten Landbesitz verfügten, der damit für die Finanzierung von Handelsunternehmungen verfügbar wurde. ${ }^{84}$ Hierdurch erfährt der für die Oberschicht der Zeit geprägte Begriff der divites eine durchaus konkrete Ausprägung. ${ }^{85}$

Im Falle Lübecks kam es zum Ende des 12. Jahrhunderts zu einer fruchtbaren Zusammenarbeit zwischen alten Kaufleuten und den neuen „Adelskaufleuten“, eine Zusammenarbeit, die ihren Niederschlag ebenso in den städtischen Bauformen, ${ }^{86}$ dem Konubium zwischen Bürgern und Ministerialen, ${ }^{87}$ der ausgeübten Ritterbürtigkeit, sichtbar zum Beispiel am Eintritt in den Deutschen Orden, ${ }^{88}$ wie in dem Benehmen und den Auf-

\footnotetext{
${ }^{80} \mathrm{Vgl}$. schon Dilcher, Rechtsgeschichte (wie Anm. 80), S. $344 \mathrm{ff}$.

${ }^{8 I}$ Enno BüNZ, Hugo von Hildesheim. Ein frühhansischer Fernhändler im Ostseeraum und der holsteinische Volksadel um 1200, in: HGbll. 113, 1995, S. 7-25.

${ }^{82}$ Hans G. TRüPER, Ritter und Knappen zwischen Weser und Elbe. Die Ministerialität des Erzstiftes Bremen (Schriftenreihe des Landschaftsverbandes der ehemaligen Herzogtümer Bremen und Verden, Vol. 12), Stade 2()()0, S. 520-529.

${ }^{83} \mathrm{Zu}$ den Vermögensverhältnissen der Ministerialität siehe u. a. TRÜPER, Ritter und Knappen (wie Anm. 82). S. 159-170, vor allem S. 166-170.

${ }^{84}$ So besaßen zum Beispiel der seit 1206 nachgewiesene dominus Alardus de Walie. civis, und sein Sohn ein Steinhaus in der Langenstraße, Häuser am Markt und Güter in Hemelingen, Hemme und Grolland. TRÜPER, Ritter und Knappen (wie Anm. 82), S. $535 \mathrm{f}$.

${ }^{85}$ Siehe zur Benennung der Lübecker Oberschicht einleitend HAMMEL-KIESOW. Neue Aspekte (wie Anm. 63), S. 62.

${ }^{86}$ Günter P. FEHRING, „Domus lignea cum caminata“. Hölzerne. turmartige Kemenaten des späten 12. Jahrhunderts in Lübeck und ihre Stellung in der Architekturgeschichte, in: Hammaburg, NF 9, 1989, Festschrift für Wolfgang Hübener, S. 271-283. Thomas BROCKOW, Mittelalterliche Wand- und Deckenmalerei in Lübecker Bürgerhäusern, in: Manfred Eickhölter und Rolf Hammel-Kiesow (Hg.), Ausstattungen Lübecker Wohnhüuser. Raumnutzungen, Malereien und Bücher im Spätmittelalter und in der frühen Neuzeit (Häuser und Höfe in Lübeck, Bd 4). Neumünster 1993. S. 41-118. S. 52, 76 und 92f. Bernd SCHIROK. Die Wandmalereien in der ehemaligen Johannisstraße 18 und in der Fischergrube 20, in: ebd. S. 269-298, hier S. 269-288. Thomas BrockOW. Manfred EICKHÖLTER and Rolf GRAMATZKI, Katalog Lübecker Wand- und Deckenmalereien des 13. bis 18. Jahrhunderts, in: ebd., S. 357-530, Katalog, Nr. 118, S. 490)ff.

${ }^{87}$ TRÜPER. Ritter und Knappen (wie Anm. 82), S. $525 \mathrm{ff}$.. für die Stadt Bremen.

${ }^{88}$ HAMMEL-KIESOW, Neue Aspekte (wie Anm. 63), S. 72. Ein anderer Hinweis sind die
} 
fassungen der Neubürger gefunden hat, wie der für Lübeck im 14., für Bremen aber schon im 13. Jahrhundert nachgewiesene Dominustitel der bürgerlichen Ratsherren verdeutlicht. ${ }^{89}$ Allein der von Rolf Hammel-Kiesow aufgezeigte Namenbestand Lübecker Bürger um 1200 zeigt, wie viele altfreie Geschlechter ein Mitglied in der neuen Stadt an der Trave platziert hatten. ${ }^{90}$ Allerdings ermöglichte diese Zusammenarbeit es anfangs den lübischen Händlern weder, ihre Waren aus Lübeck zur See herauszubekommen, noch den Ostseeraum zu dominieren.

Beiden Teilen, den Bardowickern wie den Ministerialen, fehlte zu einem erfolgreichen Handel ein ganz wesentliches Element: Schiffsraum. ${ }^{91}$ Keine der beiden Gruppen, weder die sächsisch-westfälischen noch die ritterbürtigen Kaufleute werden über nennenswerte Schiffserfahrung oder gar eigene Schiffe verfügt haben. Hierfür waren sie auf die Zusammenarbeit mit den anderen, im Ostseeraum schon längst etablierten Kaufmannsund Schiffergruppen angewiesen. Wie wichtig dieses Element für den Handel der Lübecker war, zeigt die Lübecker Chronik Helmold von Bosaus, der für das Jahr 1151 berichtet, ${ }^{92}$ dass nach anfänglichen Auseinandersetzungen mit den slawischen Nachbarn, die $1147 \mathrm{zu}$ einer Zerstörung der Siedlung und der im Hafen liegenden Kaufmannsschiffe führten ${ }^{93}$, eine Beruhigung einsetzte, so dass

Fuitque pax in terra Wagirorum, acceptique per gratiam Dei novella plantacio sensim incrementum. Forum quoque Lubicense crescebat in singulos dies, et augebantur naves institorum eius.

„Frieden herrschte im Lande der Wagrier, und die junge Pflanzung wuchs durch Gottes Gnade allmählich heran. Auch der Lübecker Markt wuchs täglich und die Schiffe seiner Kaufleute wurden täglich mehr".

Der Schiffsraum war der Tropf, an dem der Erfolg oder Misserfolg des Lübecker Handels hing - und das war allen Beteiligten klar. Unter diesem Gesichtspunkt betrachtet, gewinnen die von Seiten Heinrichs des Löwen nach 1159 eingeleiteten Verhandlungen eine ganz neue Dimension. Helmold berichtet:

Auswüchse im Turnierwesen der Lübecker Bürger zu Beginn des 13. Jahrhunderts. S. UBStL I, Nr. 47, S. 38.

${ }^{89}$ Allgemein zu diesem Komplex siehe HAMMEL-KIESOW. Neue Aspekte (wie Anm. 63), S. 67-73.

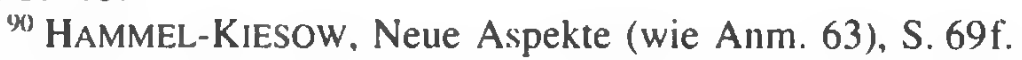

"' Siehe hierzu schon Detlev Ellmers, Die Entstehung der Hanse, HGbll. 103, 1985, S. 3-40, hier S. 11; allerdings kann seiner These einer anfänglich deutschen Schifffahrt im Ostseeraum aufgrund der neuen archäologischen Erkenntnisse nicht gefolgt werden.

92 Helmold. Chronica (wie Anm. 55), Cap. 71, S. $136 \mathrm{f}$.

${ }^{9.3}$ AM ENDE. Verfassungsgeschichte (wie Anm. 62), S. 93. 
Et transmisit dux nuntios ad civitates et regna aquilonis, Daniam, Suediam, Norwegiam, Ruciam, offerens eis pacem, ut haberent liberum commeatum adeundi civitatem suam Lubike. ${ }^{94}$

„Der Herzog aber sandte Boten zu den Städten und Reichen des Nordens, nach Dänemark, Schweden, Norwegen und Rußland, und bot ihnen Frieden, [und ließ verkünden], dass sie freien Zugang zum Handel in seiner Stadt Lübeck haben sollten".

Heinrich der Löwe sandte seine Boten an eben jene Reiche, deren Kaufleute mit ihren Schiffen den Handel auf der Ostsee sicherstellten. Wichtig ist es dabei, die Richtung seiner Einladung zu beachten: die fremden Kaufleute (und ihre Schiffe) sollen nach Lübeck kommen, nur so waren die Lübecker anfangs überhaupt erst in der Lage, ihre Waren außer Landes zu bringen. Es steht zu vermuten, dass Heinrich der Löwe die Auswahl der „civitates", an die die Boten gesandt wurden, in Absprache mit den immer mehr in den Vordergrund tretenden in Lübeck wohnhaften Kaufleuten traf. Es ist unwahrscheinlich, dass - wie es Detlef Kattinger vermutet ${ }^{15}$ - Heinrich die Boten gegen den Willen der Lübecker Kaufleute allein aus fiskalischem Interesse ausgesandt habe. ${ }^{46}$ Dieses setzte eine ausreichende Anzahl ,deutscher“ Kaufleute in Lübeck voraus, die den Handel vollständig in die eigenen Hände hätten nehmen können. Für die Frühzeit des deutschen Handels an der Ostsee aber waren die neuen Kaufleute auf die Integration in die bestehenden Systeme angewiesen, eine Integration, die durch den Handel der etablierten Mächte in der neuen Stadt gefördert werden konnte. Eine späte Reminiszenz dieser Entwicklung findet sich in der ältesten Lübecker Zollrolle, die bisher in das Jahr 1227 datiert wurde, und in der es heißt:

Nullus civis de Zwerin theloneat Lubeke. Si nec Rutenus ne Nortmannus nec Suecius nec Oningus nec Guto nec Livo, sic neque omnes gentes orientalis ... ${ }^{97}$

„Kein Einwohner Schwerins hat in Lübeck Zoll zu zahlen; auch keine Russen, keine Nortleute [Norweger], keine Schweden, keine Öländer, keine Gutnen, keine Liven und keine Angehörigen der nordischen Völker...“

Diese Bestimmungen deuten klar darauf hin, dass noch zur Zeit der Erstellung der Zollrolle mit einem Besuch dieser Nationen im Lübecker Hafen gerechnet wurde und, dass man ihrer noch immer unbedingt bedurfte. Dass dänische Kaufleute keine Erwähnung finden, könnte ein Indiz dafür sein, dass die Zollrolle aus der Zeit vor 1227, wohl aus dem Jahr

\footnotetext{
${ }^{94}$ Helmold, Chronica (wie Anm. 55), Cap. 86, S. $168 \mathrm{f}$.

9.5 KATTinger, Gotländische Genossenschaft (wie Anm. 9), S. 80 f.

${ }^{96}$ Hammel-Kiesow, Neue Aspekte (wie Anm. 63), S. 64f.

${ }^{17}$ HUB I, Nr. 223, S. 69 f. AM ENDE, Verfassungsgeschichte (wie Anm. 62), S. $46 \mathrm{f}$.
} 
1222, stammt, als Lübeck noch zum dänischen Imperium gehörte, dänische Kaufleute also „Inländer“ waren.

An diese Interpretation ließe sich dann auch problemlos die zweite und berühmteste Maßnahme Heinrichs, das nach seinem Ausstellungsort so genannte Artlenburg-Privileg von 1161, anschließen. ${ }^{98}$ Dieses Privileg regelte die Beziehungen im Handel zwischen Gotland und Sachsen beziehungsweise Lübeck. Es steht dabei explizit in der Tradition der 1134 von Kaiser Lothar ausgestellten Urkunde, die aus dem Privileg von 1161 erschlossen werden kann. In der Narratio wird berichtet, dass eine Neuregelung notwendig geworden sei, da es nach einer langen Zeit des Handelsfriedens zu einem ernsthaften Dissens gekommen sei. Worüber dieser Streit ausgebrochen war, wird nicht überliefert. Es kann aber vermutet werden, dass das langsam verstärkte Auftauchen deutscher, kapitalkräftiger Kaufleute im Ostseeraum zu einer wachsenden Konkurrenz mit den etablierten Händlern geführt hatte, was wiederum in Streit endete. ${ }^{99}$ Diese Vermutung könnte dadurch unterstützt werden, dass die Urkunde von 1161 die Rechtsgewährung für die Gutnen in Sachsen von der Gegenseitigkeit der Rechte, d.h. auch der Einräumung von Privilegien für Sachsen auf Gotland, abhängig machte. Wichtig dabei ist abermals der Hinweis auf die primäre Handelsrichtung, die in diesem Privileg beschrieben wird: die Bestätigung der Rechte der Gutnen in Sachsen wird davon abhängig gemacht, dass sie vor allem den Hafen von Lübeck regelmäßig anlaufen, et portum nostrum in Lvibyke diligencius frequentent. ${ }^{(0)}$

Bis 1161 musste also die Zahl der deutschen Kaufleute im Ostseeraum so weit zugenommen haben, dass sie einer neuen Rechtsposition bedurften. Dass hierfür allein die zwei Jahre ausreichten, die seit der „Stadtgründung" Lübecks vergangen waren, kann allerdings bezweifelt werden. Eher ist davon auszugehen, dass die allgemeine langsame Zunahme deutscher Kaufleute im Ostseeraum und ihrer Kapitalstärke zur Jahrhundertmitte einen ersten kritischen Punkt überschritten hatte, der die Deutschen langsam als Konkurrenten spürbar werden ließ. Gleichzeitig wird auch wieder das Bestreben deutlich, mehr Schiffsraum in den Hafen von Lübeck zu locken, um somit die Möglichkeiten auch der deutschen Kaufleute zu erhöhen.

Dieses ließe sich auch mit der Erwähnung von Nebenbuhlern der dänischen Kaufleute im Gotlandhandel in Verbindung bringen, die König Valdemar von Dänemark in einem Brief von ca. 1177 erwähnt. ${ }^{101}$ Ebenso

\footnotetext{
${ }^{98}$ MGH, DD, H.d.L., Nr. 48 und 49, S. $68 \mathrm{ff}$.

${ }^{99}$ KATTINGER, Gotländische Genossenschaft (wie Anm. 9), S. 87-91.

${ }^{100}$ MGH, DD, H.d.L., Nr. 48, S. 69.

${ }^{101}$ Dipl. Dan. I.3, Nr. 63, S. $93 \mathrm{ff}$.
} 
könnte die gleichmäßige Verteilung gotländischer Taufsteine des 12. und 13. Jahrhunderts - sowohl im dänischen wie im norddeutschen Raum auf ein Nebeneinander beider Kaufmannsgruppen deuten. ${ }^{102}$ Auch der Abschluss von Handelsverträgen durch Heinrich den Löwen mit König Knud und Herzog Birger von Schweden und unter Umständen mit einem unbekannten Novgoroder Fürsten bis 1180 läßt sich in diese Richtung interpretieren. $^{103}$

Von Süden her strömte im letzten Drittel des 12. Jahrhunderts vor allem mehr Kapital in den Handel des Ostseeraumes. Dieser Kapitalfluß wurde von Seiten des sächsischen Herzoges tatkräftig politisch unterstützt und zusammen mit der Durchschlagkraft des lüneburgischen Salzes im Ostseeraum verhalf dieses Lübeck und den in Lübeck vertretenen Kaufleuten zu einem größeren Einfluß in diesem Gebiet. Allerdings war die lübische Handelsflotte noch 1201 so klein, dass die Kaperung der auf der Reede vor Falsterbo liegenden Schiffe die Stadt in die Arme des dänischen Königs zwang. ${ }^{114}$

Generell muss aber noch einmal festgehalten werden, dass die frühen lübischen Kaufleute auf die enge Zusammenarbeit mit den etablierten Kräften im Ostseeraum angewiesen waren, allein aus praktischen Gründen. In der Anfangszeit des lübischen Handels bestand für sie kaum eine Möglichkeit, ihre Handelswaren mit eigenen Schiffen aus dem Lübecker Hafen herauszubringen, ganz allein aus der Tatsache heraus, dass die binnenländischen Kaufleute diese nicht besaßen. Der frühe Handel war damit nur durch Integration in das bestehende System möglich. Diese Lage sollte sich erst am Ende des 12. Jahrhunderts durch einen verstärkten Schiffbau in Lübeck ändern, ein Schiffbau, der wie unten zu zeigen sein wird, aus ökonomischen Gründen seine eigenen Bauweisen zur Folge hatte.

${ }^{102}$ Karte BILL et al., Søfarts Historie (wie Anm. 34), S. 150. Siehe zudem ausführlich zu diesem Thema Lars BERGGREN, The Export of Limestone and Limestone Fonts from Gotland during the thirteenth and fourteenth centuries, in: Lars Berggren, Nils Hybel und Annette Landen (Hg.), Cogs, Cargoes and Commerce, Maritime Bulk Trade in Northern Europe, 1150-1400, Toronto 2002, S. 143-180.

${ }^{103}$ KATTINGER, Gotländische Genossenschaft (wie Anm. 9), S. 109-117; WASE, Deutsche (wie Anm. 10), S. 29.

${ }^{\text {ItM }}$ Cum igitur omnes meliores in partem regis et fratris ducis inclinati fuissent, circa tempus piscationis, que in Sconia fieri solet, quam cives nostri frequentant - ubi etiam ipso tempore cum navibus suis et rebus sunt detenti, ita etiam ut quidam eorum in captivitatem irent - circa exaltationem sancte crucis Waldemarus dux cum expeditione gravi terram comitis intravit [...] Cives autem propter captivos suos supradictos et propter naves in Sconia detentas, animadvertentes quoque, quod ex omni parte tota in conspectu ducis parata esset, ita ut nullum introitum vel exitum nec per terram nec per mare habere potuissent, necessitate compulsi, consilio habito, nominatiores duci, cum apud Bredenvelde esset, occurrerunt et civitatem ei tradiderunt sicque suos captivos cum navibus et omnibus ablatis receperunt. Arnold von Lübeck, Chronica (wie Anm. 75), Cap. VI.13, S. 234. 


\section{Schleswig und Lübeck: Zwei streitende Schwestern?}

Aus den vorangegangenen Ausführungen ist klar geworden, dass der Aufstieg Lübecks in erster Linie wenig mit dem Transithandel zwischen Ostund Nordsee zu tun hatte, ein Befund, der sich z. B. auch durch die Verteilung von Münzen und Hortfunden deutlich untermauern lässt: auch hier wird die Verteilung des Handelsverkehres über eine Nordroute Westfalen-Schleswig-Russland und eine Südroute Niedersachsen-SlawenlandOstseeraum deutlich. ${ }^{105}$ Diese Feststellung hat nun erhebliche Auswirkungen auf die Bewertung des Handels der Stadt Schleswig. Vollständig unter dem Eindruck der beherrschenden Rolle Lübecks im Handel des 12. Jahrhunderts sind die wenigen historischen und die vielfältigen archäologischen Quellen bisher immer in dem Sinne interpretiert worden, dass der Handel der Stadt an der Schlei 1159 spätestens aber um 1239 ein jähes Ende gefunden habe. ${ }^{106}$ Allerdings lassen die gesicherten Fakten auch ganz andere Schlüsse zu.

Für die These des Abstieges der Stadt von einer Fernhandelssiedlung zu einem ländlichen Markt zu Beginn des 13. Jahrhunderts werden in der Forschung vor allem zwei Argumente angeführt: zum einen, dass der königliche Landesherr zu Beginn des 13. Jahrhunderts die Stadt radikal umbauen und einen Zentralmarkt einrichten ließ, und zum anderen, dass es den Dominikanern gestattet wurde, 1239 ihr Kloster auf einem Teil der alten Hafenanlagen zu errichten. ${ }^{107}$

Was das erste Argument anbelangt, so erscheint es wenig wahrscheinlich, dass ein Herrscher sich die Einnahmen aus einer Handelsstadt im wahrsten Sinne des Wortes verbaut, indem er eine funktionierende Hafenstruktur durch etwas anderes ersetzt, was ihm weniger Zolleinnahmen einbringen würde. Das Engagement des dänischen Königs lässt sich nur dadurch erklären, dass er sich mit dem Umbau dieser Hafenstadt erhöhte Zolleinnahmen versprach. Zudem ist die Argumentation, dass die Einrichtung eines Zentralmarktes mit Rathaus als Zeichen einer Ausrichtung auf einen ländlichen Markt zu werten sei, im Lichte der Stadtgeschichtsforschung nicht haltbar und ist wohl mehr als ein Zirkelschluss aus den

\footnotetext{
${ }^{105}$ Siehe hierzu maßgeblich HAMMEl-KIESOW, Determinanten (wie Anm. 22), im Druck.

1106 VOGEL, Der Schleswiger Hafen (wie Anm. 24), S. 195.

${ }^{107}$ Siehe hierzu ausführlich Carsten JAHNKE, „... und er verwandelte die blühende Handelsstadt in ein unbedeutendes Dorf". Die Rolle Schleswigs im internationalen Handel des 13. Jahrhunderts, in: Von Menschen, Ländern, Meeren. Festschrift für Thomas Riis zum 6.5. Geburtstag, hg. von Gerhard Fouquet, Mareike Hansen, Carsten Jahnke und Jan Schlürmann, Tönning 2006, S. 251-268.
} 
angeblichen lübischen Verhältnissen aufzufassen, denn als neutrale Interpretation. $^{108}$

Anders sieht es mit der Einrichtung eines Klosters im Schleswiger Hafenbereich aus. Hier ist es im Anschluss an die 2006 erschienene Arbeit von Carsten Jahnke ${ }^{109}$ zu heftigen Auseinandersetzungen mit der Schleswiger Stadtgeschichtsforschung gekommen. ${ }^{10}$ Ausgangspunkt der Differenzen ist die Frage, ob man die Einrichtung eines Bettelklosters im Hafenbereich als eine Modernisierung und damit auch als Wirtschaftsförderung verstehen kann, und, wie viel Platz dieses Kloster wirklich im Hafenbereich einnahm. Diese Diskussionen können noch nicht als abgeschlossen gelten, haben aber durch die Entdeckung weiterer Hafenanlagen in Schleswig im Jahre 2007 neue Nahrung erhalten.

Allerdings lassen sich auch, wenn man den letzten Punkt außer Acht lässt, genügend Punkte für eine Neubewertung des Schleswiger Handels in dieser Zeit finden. So hatte zum Beispiel der dänische König noch 1175 Anteile an einer societas mit einem Schleswiger Bürger, die ein besonders großes Schiff zum Handel mit Wachs in Russland bauen lie $\beta^{11 \prime}$ und 1177 war der Herrscher selbst Mitglied der dänischen Knudsgilden. ${ }^{1 / 2}$ Besonders wichtig ist es auch, auf die zentrale Rolle hinzuweisen, die Schleswig im Gefüge der Machtrepräsentation des dänischen Königtums einnahm. Hier befand sich nicht nur eine der wichtigen Pfalzen, hier wurden vor allem auch wichtige Hoftage und Krönungen durchgeführt und das Reich nach Außen hin repräsentiert. ${ }^{113}$ Es ist daher äußerst unwahrscheinlich, dass der prestigemäßigen Hochachtung, die die Könige bis 1218 und darüber hinaus dieser Stadt entgegenbrachten, eine wirtschaftspolitische Vernachlässigung gefolgt sein sollte.

So ist also nach dem Verhältnis zwischen Schleswig und Lübeck am Ende des 12. Jahrhunderts und hier vor allem nach dem Übergang der Transitfunktion von Schleswig-Hollingstedt nach Lübeck-Hamburg zu fragen. Die oben geschilderte Entwicklung des lübischen Handels in Südrichtung wird selbstverständlich zu einer Veränderung des Schleswiger Handels geführt haben. Allerdings ist es sehr zweifelhaft, ob damit ein wirtschaftlicher Abstieg einhergegangen ist, zu verschieden war die jeweilige Kaufleuteklientel. Schleswig lebte vom Handel mit den Fluss- und See-

\footnotetext{
${ }^{108}$ Siehe JAHNKE, „... und er verwandelte" (wie Anm. 108), S. 257.

109 JAHNKE, „... und er verwandelte" (wie Anm. 108).

110 Siehe jetzt RADTKE, Schleswig (wie Anm. 20), S. 330, Note 52.

"1'R. PAULI, Aus den Mirakeln des heiligen Thomas von Canterbury. HGbll. 5, 1875. S. $125 \mathrm{ff}$. RADTKE, Schleswig und Soest (wie Anm. 29), S. $458 \mathrm{f}$.

$112 \mathrm{Vgl}$. Hans T. GILKAR. In honorem sancti Kanuti martyris, Konge og Knudsgilder i det 12. århundrede. in: Scandia 1980:2, S. 121-161, hier S. $129 \mathrm{f}$.

113 Vgl. JAHNKE, ,... und er verwandelte" (wie Anm. 108), S. 262.
} 
städten resp. von den Städten mit guter Flussanbindung, von Köln, Soest, Medebach und Bremen, Lübeck vom Handel mit dem Binnenland in Sachsen und dem östlichen Westfalen. Diese binnenländischen Kaufleute werden natürlich in Schleswig ausgefallen $\operatorname{sein}^{1 / 4}$ und vielleicht kann man in diesem Ausfall die erstc Motivation für den Modernisierungsschub der Schleistadt sehen. Eine wirkliche Krise konnte dieser Ausfall allerdings nicht bedeuten, da Lübeck für Kölner, Soester oder Bremer Kaufleute keine ernsthafte Alternative darstellen konnte.

Dieses sollte sich erst ändern, als die Kaufleute der Travestadt ihre Handelsrichtung vom Nord-Südverkehr auf den Ost-Westverkehr umorientierten, ein Vorgang, der sich sehr gut für das beginnende 13. Jahrhundert fassen lässt.

Das $\mathrm{A}$ und $\mathrm{O}$ der Transitfunktion Lübecks ist eine funktionierende Westanbindung und ein leistungsfähiger Westhafen mit Zugang zur Nordsee. Wie selbstverständlich wurde in der älteren Literatur Lübeck immer im Zusammenhang mit Hamburg gesehen. Doch lässt dieser Gedanke außer Acht, dass das heutige Hamburg, so wie wir es verstehen, erst durch die Stadterweiterung des Jahres 1188/89 seinen Ausgangspunkt nahm. ${ }^{115}$ Auch war diese Stadt nicht dazu angelegt worden, um die Rolle Hollingstedts im Transithandel zu übernehmen. Die hamburgische Handelsrichtung waren, wie aus dem „Gründungsprivileg“ Friedrich Barbarossas und den Zollurkunden der holsteinischen Grafen hervorgeht, die elbaufwärts gelegenen Getreideanbaugebiete. So wurde Hamburg schon sehr früh vom Zoll in Boitzenburg, Geesthacht, Eslingen und Krauel befreit und einzig dem Lauenburger Zoll unterworfen. ${ }^{116}$ Und von Barbarossa hatte die Stadt eine Zollfreiheit auf der Elbe von Hamburg bis zum Meer sowie im Gebiet des Grafen für Holz, Asche und Getreide erhalten,

\footnotetext{
${ }^{114}$ Zur Rolle der Sachsen und Westfalen in Schleswig/Haithabu siehe RADTKE, Schleswig im vorlübischen Geldverkehr (wie Anm. 8), S. 392. Generell ist die Rolle der binnendeutschen Kaufleute im Ostseeraum dieser Zeit bisher ein noch nicht hinreichend untersuchtes Feld. So zeigt zum Beispiel die Verteilung der Dortmunder Münzen der Zeit von 950 bis 1140 das große Interesse, das diese Kaufleute dem Ostseeraum entgegengebracht haben, ohne dass aber völlig klar wird, welchen Weg die Kaufleute (und ihre Münzen) letztendlich genommen haben. Siehe hierzu die Verteilungskarte in: Ferne Welten - Freie Stadt, Dortmund im Mittelalter, hg. v. Matthias OHM, Thomas SCHILP und Barbara WELZEl, Bielefeld 2006, S. 115.

115 Vgl. hierzu K. Richter, Hamburgs Frühzeit bis 1300, in: Hamburg, Geschichte einer Stadt und ihrer Bewohner, hg. v. W. Jochmann und H.-D. Loose. Hamburg 1982, S. 17-100, hier S. 59-65. Gerhard ThEuERKAUf, Der Hamburger Hafen vom 12. bis zum 16. Jahrhundert, in: Beiträge zur hansischen Kultur-, Verfassungs- und Schiffahrtsgeschichte, hg. von Horst Wernicke und Nils Jörn (Hansische Studien, Bd. X), Weimar 1998, S. 129-143, hier S. $131 \mathrm{f}$.

${ }^{116}$ SHUB I, Nr. 329, S. 150. Theuerkauf, Hamburger Hafen (wie Anm. 116), S. 132 mit Hinweisen zur Datierung.
} 
bzw. sich in der Fälschung dieses Privileges 1265/66 selbst zugesprochen. ${ }^{117}$ Wiederum ist auffällig, dass in der rekonstruierbaren und in der gefälschten Fassung des Privileges von 1189 der Transitweg zwischen Hamburg und Lübeck keine Erwähnung findet. ${ }^{118}$

Die Verbindung zwischen der Trave- und der Elbestadt entwickelte sich erst spät und ganz offensichtlich durch die nach 1201 einsetzende pax Valdemariana, durch die die Befahrung einer so langen Transitroute ohne Gefahren möglich wurde. Faßbar wird die Entwicklung allerdings nur durch verschiedene Schlaglichter, die die einzelnen Stufen aber recht anschaulich beleuchten. So ist es zum Beispiel bezeichnend, dass der frühe Stadtgrundriss Lübecks nur eine Nord-Südachse, vom Burgtor bis zur Mühlenbrücke, aber keinen Anschluss an eine mögliche Westroute vorsah. Der Übergang nach Westen, d.h. in Richtung Oldesloe und Hamburg, erfolgte in dieser Zeit über die Altefähre im Norden der Stadt. ${ }^{119}$ Diese Transportausrichtung wurde erst um 1216 (aber noch vor der Ummauerung der Stadt) mit der Errichtung der Holstenbrücke geändert, ${ }^{120}$ die eine feste Anbindung an die Route nach Hamburg darstellt. Zu dieser Zeit muss das Verkehrs- und Handelsaufkommen nach Westen gestiegen sein, so dass sich der Bau einer festen Brücke zusammen mit den späterhin notwendigen Verteidigungsanlagen gelohnt hat. Diese Änderung im Verkehrsstrom wird dann 1226 deutlich, als sich die Stadt ein neues Privileg fälschte und es dem Kaiser vorlegte. Nicht nur, dass jetzt jeglicher Hinweis auf den Zoll in Artlenburg verschwunden ist, sondern die Lübecker lassen sich nun eine Zollfreiheit in Oldesloe bescheinigen und vom Kaiser versichern, dass „sich kein Fürst, Herr und Edelmann der umliegenden Gebiete erdreisten [solle], zu verhindern, daß das Notwendige von überallher in die Stadt Lübeck gebracht werde, es sei von Hamburg, von Ratzeburg, von Wittenburg, von Schwerin, auch aus dem ganzen Lande Borwins [...]". ${ }^{121}$ Mit diesen Worten beschreibt der Lübecker Rat sehr deutlich einen Zwischenstand auf dem Wege vom Nord-Süd- zum Ost-Westhandelszentrum.

Parallel zu dieser Entwicklung ist festzustellen, dass Lübeck und Hamburg zusammen oder kurz hintereinander Privilegien im Ausland erwar-

\footnotetext{
${ }^{117}$ MGH. DD FI. Nr. 1001, S. 294. Zu diesem Zweig des hamburgischen Handels siehe KIESSELBACH, Wirtschaftliche Grundlagen (wie Anm. 51), S. 112-121. S. a. THEUERKAUF, Hamburger Hafen (wie Anm. 116), S. 134f.

${ }^{118}$ MGH. DD FI, Nr. 1001. Regest, S. 291-294.

${ }^{119}$ Ich danke Prof. Rolf Hammel-Kiesow für diesen Hinweis.

${ }^{120}$ SHUB I, Nr. 319, S. 146.

${ }^{121}$ Antjekathrin GRASSMANN, Die Urkunde, in: Lübeck 1226, Reichsfreiheit und frühe Stadt, Lübeck 1976, S. 9-19, hier S. 18.
} 
ben. ${ }^{122}$ Für dieses verstärkte Westinteresse spricht ebenfalls, dass nach 1226 eine verstärkte Privilegierung Lübecks im Westen des Reiches einsetzte. $^{123}$

Allerdings hatte sich zu diesem Zeitpunkt die „Hamburgische Straße“ noch nicht vollständig etabliert. Doch führte der erhöhte Transitverkehr jetzt dazu, dass sich beide Städte annäherten, ihre Handelspolitik in mehreren Schritten aufeinander abstimmten und versuchten, die Verbindung zu sichern und alle Zollstellen abzuschaffen. In der Zeit zwischen 1236 und 1266 versichert Hamburg seinen Lübecker Freunden, dass diese in der Elbestadt das gleiche Recht genießen sollten, wie die Hamburger selbst, ${ }^{124}$ 1234, 1238 und 1251 ist der Handel von Bremer und Stader Bürgern auf dem Wege nach und in Lübeck bezeugt, wo sie allerdings, wie die Lübecker, in Oldesloe Zoll zahlen mussten. ${ }^{125}$ Im Jahre 1240 gewährten die Gebrüder Marquart und Heinrich Parkentin auf Wunsch des Herzogs von Sachsen und aus Freundschaft für die Bürger Lübecks allen Kaufleuten freien Durchzug auf der „Hamburger Straße“ (platea hamburgensis) in ihrem Gebiet und die Benutzung der Fähre zu Parkentin, die allerdings nicht auf der Route über Oldesloe liegt. ${ }^{126}$ Zur gleichen Zeit kauften die Hamburger den holsteinischen Grafen für $200 \mathrm{~m}$. Silber aus dem Oldesloer Zoll heraus, ${ }^{127}$ und am 12. März 1241 konnten dann die Lübecker vom Herzog von Sachsen erwirken, dass sie de orientali mari ad occidentale mare (que) Osterse et westerse wlgariter nuncupantur, precise De lubeke deorsum sive inferius usque hamburch et de hamburch sursum

\footnotetext{
${ }^{122}$ Siehe ausführlich JENKS, Die Welfen (wie Anm. 76), S. 509f.

${ }^{123} \mathrm{Vgl}$. JENKS, op. cit., S. $512 \mathrm{ff}$.

${ }^{124}$ SHUB I, Nr. 485, S. 220. HUB I. Nr. 239, S. 81. Die Datierung ist umstritten. Klaus WRIEDT, Die ältesten Vereinbarungen zwischen Hamburg und Lübeck, in: Civitatum Communitas, Festschrift Heinz Stoob zum 65. Geburtstag. hg. von Helmut Jäger, Franz Petri und Heinz Quirin. Köln, Wien, 1984, Teil 2, S. 756-764, legt als terminus post quem das Jahr $1236(-41)$ fest, tendiert aber dazu, die Versicherung aus politischen Gründen in das Jahr $1266 \mathrm{zu}$ legen (S. 763). Anhand der politischen und ökonomischen Verbindung, die bis 1266 zwischen Hamburg und Lübeck entstanden war. ist m. E. eine so späte Entstehung unwahrscheinlich. Sie würde letztendlich bedeuten. dass das ökomisch-politische Verhältnis Hamburgs 1266 zum Grafen von Holstein enger gewesen wäre als das zu Lübeck.

${ }^{125}$ SHUB I, Nr. 575, S. 258f., Brem. UB I, Nr. 178, S. 214. Urkundenbuch der Stadt Stade (Stader UB), hg. von Jürgen BOHMBACH (Veröffentlichungen der Historischen Kommission für Niedersachsen und Bremen, Bd. 37. und aus dem Stadtarchiv Stade, Bd. 1, zugleich Brem. UB, 12. Abt.), Hildesheim, Stade 1981, Nr. 33, Nr. 34. S. 31 und Nr. 36, S. 32.

${ }^{126}$ SHUB I. Nr. 604, S. 272, UBStL I. Nr. 89, S. 91.

${ }^{127}$ Hamb. UB I. Nr. 818, S. 671-675, hier S. 672. Wy koften eme den tolne to Odeslo un hern Ecbrechte van Wulfenbuttele umme twehundert lodighe mark suluere. Dieser Eckbrecht von Wolfenbuittel de Asseburg erscheint in den Braunschweigischen Urkunden u.a. im Gefolge der Gräfin von Dassel. (Braunschw. UB I, Nr. 21, S. 18) und ist u. U. der Sohn des bekannten Ministerialen Gunzlin von Wolfenbüttel. In den nächsten Jahrhunderten wurden die Hamburger aber immer wieder dem Oldesloer Zoll unterworfen. SCHRECKER, Straßennetz I (wie Anm. 75), S. $81 \mathrm{f}$.
} 
usque luebeke per terram nostram, ,vom östlichen Meere zum westlichen Meere, welche allgemein Ost- und Westsee genannt werden, genauer von Lübeck bis hinunter nach Hamburg und von Hamburg hoch nach Lübeck in unserem ganzen Gebiet" von allem Zoll, mit Ausnahme des Heringzolles, befreit wurden und ihnen gegen cine geringe Gebühr Geleit zugesagt wurde - auch wenn der Herzog nicht für ihre Sicherheit garantieren wollte. Diese Verhältnisse wurden dann am 10. November 1241 durch die Nachfolger des alten holsteinischen Grafen ${ }^{128}$ und 1247 erneut bestätigt. ${ }^{129}$

Damit war die Hamburger Straße Wirklichkeit und als Konsequenz hieraus kam es zu den beiden berühmten Verträgen zwischen Lübeck und Hamburg des Jahres 1241, ${ }^{131}$ die die Sicherheit auf der Hamburger Straße sichern sollten und die in der älteren Literatur als die Gründungsstunde der Hanse angesehen wurden. ${ }^{131}$ Ist letzteres auch mehr als interpretabel, so kann doch gesagt werden, dass spätestens jetzt die Strecke Lübeck-Hamburg der Route Schleswig-Hollingstedt gleichgestellt war.

Die oben geschilderten Abläufe lassen sich mit guten Gründen so interpretieren, dass sich die Verkehrsströme im südlichen Ostseeraum zu Beginn des 13. Jahrhunderts schrittweise geändert haben und, dass diese Veränderung nicht zeitgleich mit der „Gründung" Lübecks einhergegangen ist. Voraussetzung für diese Veränderung war - betrachtet man die politische Lage in diesem Raume - der Frieden, den die Einverleibung Holsteins in das dänische Reich nach 1201 allgemein gebracht hatte und der bis 1226 anhielt. Die starke dänische Zentralmacht, hier vor allem vertreten durch Albrecht von Orlamünde, konnte den regionalen Adel so weit zügeln, dass die Befahrung der erheblich längeren Strecke zwischen Lübeck und Hamburg ebenso sicher wurde, wie die der Strecke zwischen Hollingstedt und Schleswig. Es ist eine Ironie der Geschichte, dass diese Friedensperiode eben zum Abstieg der Handelsbedeutung Schleswigs, wie sie seit dem 14. Jahrhundert bezeugt ist, und letztendlich zum Verlust des Transitverkehres für Dänemark geführt hat.

Allerdings kann nicht nur die Befriedung des Transitweges zwischen Hamburg und Lübeck als alleinige Ursache dafür angenommen werden,

\footnotetext{
${ }^{128}$ Hamb. UB 1, Nr. 520, S. 444. Siehe hierzu Karl Koppmann, Zum Lübisch-Hamburgischen Bündnis vorn Jahre 1241, in: ZGesSHG 6, 1876, S. 125-132. DERS., Der Vertrag zwischen Hamburg und Lübeck vom Jahre 1241, in: HGbll., Jg. 1872. Nr. IV, S. 67-76.

${ }^{129}$ SHUB I, Nr. 679, S. 301 f. Zur weiteren Entwicklung bis zum Ende des 13. Jahrhunderts siehe ausführlich KIESSELBACH, Wirtschaftliche Grundlagen (wie Anm. 51), S. 95-103.

${ }^{130}$ Hamb. UB I, Nr. 524 und 525, S. 446f. Siehe hierzu auch JENKS, Die Welfen (wie Anm. 76), S. 507 f. und Note 74.

${ }^{131}$ Siehe hierzu Wriedt, Die ältesten Vereinbarungen (wie Anm. 125), S. 756. Hans-Friedrich SCHÜTT, Dänemark und Schleswig-Holstein in ihrem Verhältnis zu Lübeck und zur Hanse, in: BlldtLg 126, 1990, S. 37-65, hier S. 41.
} 
dass die Kaufleute einen $70 \mathrm{~km}$ langen Weg den $18 \mathrm{~km}$ zwischen Hollingstedt und Schleswig vorgezogen haben, denn es ist einfach unökonomisch, Waren vier Tage über Land zu transportieren, wenn es auch in einem geht. ${ }^{132}$ Aus diesem Grunde muss man nach weiteren Erklärungsmöglichkciten suchen.

Eine dabei immer wieder angeführte These ist, dass es für den Kaufmann, z. B. aus Soest, näher zum Meer gewesen sei, wenn er die Hamburger Straße benutzt hätte, anstatt von Hamburg über Land nach Schleswig zu reisen. ${ }^{133}$ Diese These verkennt allerdings, dass Hamburg zu dieser Zeit überhaupt keinen Anschluss an das internationale Straßennetz nach Schleswig besaß: der von Norden kommende Heerweg bog nämlich hinter Rendsburg nach Itzehoe ab, von wo aus ein Anschluss nach Stade-VerdenMinden-Paderborn-Mainz bestand. ${ }^{134}$ Auch scheint der Landweg Rendsburg-Schleswig handelsmäßig nur wenig frequentiert gewesen zu sein, erhob der König in Schleswig doch auf alle von Rendsburg kommenden Handelskarren nur den halben Zoll im Vergleich zu denen aus Hollingstedt. ${ }^{135}$ Zudem fehlt jeder Beleg für einen Landhandel zwischen Hamburg und Schleswig, der nicht nur unsicher, sondern ökonomisch auch wenig sinnvoll gewesen wäre. Ebenso unklar ist es, warum westfälische Kaufleute, wenn sie denn die Landroute über den Teutoburger Wald und Süntel und Deister gewählt hätten, nach Hamburg und nicht nach Artlenburg hätten ziehen sollen. ${ }^{136}$

Die Entfernungs- und Wegeverhältnisse sprechen nicht für einen Transithandelsweg zwischen Lübeck und Hamburg. Dass dieser sich trotzdem entwickelte und $\mathrm{zu}$ seiner beherrschenden Stellung aufsteigen konnte, muss also durch andere Ursachen zu erklären sein - auch wenn hier abermals nicht von einer Monokausalität ausgegangen werden kann.

Mit dem Ausbau und der Sicherung des Weges Lübeck-Hamburg gingen weitere Prozesse parallel, die den Veränderungsprozess verstärkten.

\footnotetext{
${ }^{132}$ Siehe hierzu schon Ellmers, Hanse (wie Anm. 91), passim.

${ }_{133}^{133}$ ELLMERS, Hanse (wie Anm. 91), S. 9.
}

${ }^{1.34}$ Alfræđi Íslenzk. Islandsk Encyklopiedisk Litteratur. I. Cod. Mbr. AM 194, 80, hg. von Kristian KÅlund, København 1908. Janus MøLler JEnSEN, Vejen til Jerusalem. Danmark og pilgrimsvejen til Det hellige Land i det 12. århundrede: en islandsk vejviser, in: Ett annat 1100-tal. Individ, kollektiv och kulturella mönster i medeltidens Danmark, hg. von Peter Carelli, Lars Hermanson und Hanne Sanders, Lund 2004, S. 284-328, hier S. $298 \mathrm{ff}$. und Appendiks 1. Tabel I. S. 322f. Siehe auch Historischer Atlas Schleswig-Holstein, Vom Mittelalter bis 1867. hg. von Jürgen H. IBS, Eckard DEGE und Henning UNVERHAU, Neumünster 2004, S. 81, Karte II.

${ }^{135}$ Danmarks Gamle Købstadslovgivning 1, hg. von Erik KROMAN, København 1951, Slesvig, Nr. 1, §30, S. 9.

${ }^{136}$ Es sei denn, man geht davon aus, dass sie über Osnabrück nach Bremen und nicht nach Hannover gezogen sind, und selbst dann wäre der Anschluss Stade-Itzehoe der näherliegende gewesen. 
Die an der südlichen Ostseeküste ostwärts voranschreitende „Kolonisierung" führte zum einen dazu, dass sich die Absatzsituation in diesem Raum zugunsten der Aufnahme westlicher Luxusgüter änderte, was zum anderen durch die „Stadtwerdung“ alter slawischer Handelspunkte und dem Einströmen neuen Kapitales durch deutsche Kaufleute verstärkt wurde. Der Ablauf dieses Prozesses ist allgemein bekannt und kann gut durch die "Stadtgründungen“" und Stadtrechtsverleihungen belegt werden: so zum Beispiel Riga 1201, Rostock 1218, Wismar 1228, Stettin 1237 und Danzig 1238. ${ }^{137}$ Der alte Ost-Westhandelsstrom, der direkt zwischen Novgorod und Schleswig pulsierte wurde so zum einen aufgesplittert und zum anderen mehr und mehr an die südliche Ostseeküste gezogen. Zum anderen führte der Ausbau der Schonischen Messen dazu, dass sich die Handelsrouten der Nordseestädte verlagerten, die nun nicht mehr nach Schleswig und Norwegen handelten, sondern ebenfalls zu Beginn des 13. Jahrhunderts den Reiz des Öresundmarktes entdeckten und ihren Handel nun auf Skanör und Falsterbo bündelten. ${ }^{138}$ Auch diese so genannte „Ummelandfahrt" entwickelte sich prozessual, bis sie 1251 eindeutig kodifiziert wurde. ${ }^{139}$

Bildlich gesprochen wurde der Schleswiger Osthandel seit Beginn des 13. Jahrhunderts von einer klassischen Zangenbewegung im Süden und Norden des Ostseeraumes bedroht. Die deutschen Kaufleute des Rheinlandes und Westfalens nutzten mehr und mehr die Südroute via Hamburg und die Zuiderzee- und Nordseeanrainer fuhren mehr und mehr direkt nach Schonen, um dort die in den Ostseehandel eingewanderten aber auch die alten Kaufmannsgruppen zu treffen. Die kurze und effektive Strecke über Schleswig verlor dabei zur Mitte des 13. Jahrhunderts zusehends an Bedeutung.

Bei der Betrachtung dieser Entwicklung stellt sich die Frage nach den Ursachen für diesen beschleunigten Umbau und nach den Reaktionen von Seiten der dänischen Zentralmacht. Die Ursachen für diese Entwicklung waren, wie oben angedeutet, mit Sicherheit vielfältig und können nicht monokausal mit der Gründung der Stadt Lübeck verbunden werden. Ein wesentliches Element dürfte dabei aber die "Stadtwerdung" Hamburgs und Lübecks und die damit verbundenen rechtlichen Vorteile gewesen sein. Es ist nämlich durchaus bezeichnend, dass die kosten- und zeitbewussten Kaufleute des 13. Jahrhunderts den wesentlich längeren und zeit-

\footnotetext{
${ }^{137}$ Philippe Dollinger. Die Hanse. Stuttgart ${ }^{+}$1989, S. 49-52.

${ }^{138}$ Carsten JAHNKE, Das Silber des Meeres. Fang und Vertrieb von Ostseehering zwischen Italien und Norwegen, 12. bis 16. Jahrhundert (QDhG, N.F., 49), Köln, Weimar. Wien 2000. S. $69 \mathrm{f}$.

${ }^{139}$ HUB I. Nr. 411 , S. 133f. und Nr. 423, S. $134 \mathrm{f}$.
} 
weise unsicheren Weg zwischen Elbe und Trave dem kurzen und sicheren zwischen Treene und Schlei vorzogen. Einer der Gründe ist sicherlich in der rechtlichen Situation in beiden Städten zu suchen. Die Kaufleute, die über Hamburg und Lübeck handelten, taten dieses in gewohnter Rechtsumgebung unter den Prämissen der neu geschaffenen städtischen Gerichtsbarkeit. Dieses zusammen mit der nun beginnenden Netzwerkbildung zwischen den Städten muss ein ungeheurer Vorteil gewesen sein, der unter anderem dadurch deutlich wird, dass die Hamburger den Lübeckern dieses noch im 13. Jahrhundert schriftlich versichern mussten. ${ }^{140}$

Ein zweiter, wichtiger Punkt war mit Sicherheit auch die Stadtentwicklung an Elbe und Trave. Die hamburgische Stadtfläche (und vor allem Stadtbebauung) verfünffachte sich bis $1250,{ }^{141}$ so dass die Stadt eine gröBere handelspolitische Rolle spielte, die durch den neuen Transitweg bekräftigt wurde und die Anziehungskraft der Stadt wiederum verstärkte. Hamburg entwickelte dadurch eine eigene Position, die zwar teilweise mit dem neuen Transithandel verbunden war, aber nicht ausschließlich darauf beruhte. Hamburg war von Anfang an kein reiner Transithafen im OstWesthandel, sondern besaß eigene Handelsinteressen, so zum Beispiel den Absatz des Hamburger Bieres oder die Vermarktung märkischen Getreides. $^{142}$

Auch Lübeck lebte im 13. und 14. Jahrhundert nicht nur vom Transithandel zwischen Ost und West, sondern anfangs primär vom Salzhandel mit Lüneburg und vom Heringshandel. Dazu entwickelte sich die Stadt zur gleichen Zeit ebenfalls zu einer bedeutenden Brauereistadt. ${ }^{143}$ Ebenfalls erlebte die Tavestadt durch die umfangreiche Stadterweiterung in dieser Zeit eine markante Erweiterung des Stadtareales ${ }^{144}$, so dass auch von ei-

\footnotetext{
${ }^{140}$ Siehe Anm. 124.

14| Siehe hierzu T. LüDECKE. Stade und Hamburg. Zur Entwicklung ihrer Hafen- und Stadttopografie im Mittelalter. Eine vergleichende Skizze, in: Maritime Topography and the Medieval Town (wie Anm. 24), S. 95-108, hier S. 102-107.

${ }^{142}$ Siehe hierzu schon Rolf SPRANDEL, Der Hafen von Hamburg, in Heinz Stoob (Hg.), Seeund Flusshäfen vom Hochmittelalter bis zur Industrialisierung, Köln, Wien 1986. Städteforschung, Vol. XXIV, S. 193-210, hier S. 193f. und 198f.

${ }^{143}$ Wolfgang FRONTZEK. Das städtische Braugewerbe und seine Bauten vom Mittelalter bis zur Neuzeit, (Häuser und Höfe in Lübeck, Band 7), Lübeck 2005, S. 57. Siehe zum um 1250 beginnenden lübisch-wendischen Bierexport nach Dänemark Nils HYBEL und Bjørn POULSEN, The Danish resources c. 1000-1550, Growth and Recession (The Northern World, Vol. 34), Leiden 2007, S. 365f.

It4 Siehe mit weiteren Hinweisen Manfred GLÄSER, Der Lübecker Hafen des 12. und 13. Jahrhunderts. Grabungsergebnisse und Rekonstruktionen, in: ZVLGA 69, 1989, S. 49-73, hier S. 64f. Des weiteren Günter P. FEHRING und Rolf HAMMEL, Die Topographie der Stadt Lübeck bis zum 14. Jahrhundert. in: Stadt im Wandel: Kunst und Kultur des Bürgertums in Niedersachsen und Norddeutschland, 1150-1650, hg. von Cord Meckseper, Stuttgart 1985, S. 167-190, hier S. 173-177. Andreas RANFT, Lübeck um 1250 - eine Stadt im "take-off“,
} 
nem höheren Konsum in allen Bereichen ausgegangen werden kann. Die beiden Endpunkte der neuen Transitlinie waren dadurch nicht nur Durchgangshäfen, sondern entwickelten sich auch zu Handelszielen an sich.

Nun ging die geschilderte Entwicklung natürlich nicht im Geheimen ab und deutete sich über viele Jahre an. So stellt sich also die Frage, wie die schleswigsche Obrigkeit, d.h. das dänische Königtum, auf diese Entwicklung reagiert hat, ein Problem, das relativ viel Kopfzerbrechen bereitet hat. Die ältere Forschung ging davon aus, dass Valdemar Sejr Lübeck direkt zuungunsten Schleswigs bevorzugt habe. ${ }^{145}$ Dem steht entgegen, dass der König keine Skrupel verspürte, den Lübecker Hafen immer dann zu sperren, wenn er ein politisches Druckmittel gegen die deutsche Ostbewegung bzw. den Bischof von Riga benötigte. ${ }^{146}$ Auch erscheint es merkwürdig, dass die Stadt Schleswig den Rahmen für Krönungen und repräsentative Verhandlungen mit ausländischen Mächten abgab und gleichzeitig durch den König wirtschaftlich vernachlässigt worden sein sollte.

Vor dieser Folie lassen sich die Erkenntnisse, die vor allem die Archäologie gewonnen hat, neu deuten. Ausgangspunkt des Schleswiger Wohlstandes war der reine Transithandel, das bedeutet, dass die Stadt vollständig von ihrem Westhafen abhängig war. Hier nun haben die Ausgràbungen der letzten Jahre ergeben, dass die Entwicklungen in Hollingstedt bis zum Ende des 12. Jahrhunderts sehr zukunftsorientiert waren. So wurden bis 1200, wie später in Stade und Hamburg, die Hafenflächen an der Treene künstlich erhöht, um so sichere Lagerflächen zu schaffen und das Anlegen der Schiffe zu erleichtern. ${ }^{147}$ Allerdings, und das ist der erste bemerkenswerte Unterschied, blieb der letzte Stadtgründungsimpuls hier aus. Andererseits durchlief Schleswig zu Beginn des 13. Jahrhunderts die oben erwähnten baulichen Veränderungen, die der Stadt ein modernes Aussehen verliehen. Dieser Umbau, vor allem die Tatsache, dass die alte Schleswiger Stadtkirche abgerissen und an den Rand des neu entstandenen Marktes verlegt wurde, lässt nur den Schluss zu, dass dieser Transithafen

in: Europas Städte zwischen Zwang und Freiheit. Die europäische Stadt um die Mitte des 13. Jahrhunderts, hg. von Wilfried Hartmann. Regensburg 1995, S. 169-188.

${ }^{14.5}$ HoffmanN, Schleswig und Lübeck (wie Anm. 4), S. $35 \mathrm{f}$.

${ }^{146}$ Kurt Villadas Jensen, Danske Korstog, Krig og mission i Østersøen, København 20(04, S. 220-225. Zu den handelspolitischen Auswirkungen siehe RADTKE, Schleswig und Soest (wie Anm. 29), S. 461f. JenKS, Die Welfen, (wie Anm. 76), S. 502ff.

${ }^{147}$ Klaus BRANDT, Neue Ausgrabungen in Hollingstedt, dem Nordseehafen von Haithabu und Schleswig. Ein Vorbericht, in: Offa, Bd. 54/55, 1997/1998, Festschrift für Kurt Schietzel, S. 289-307, hier S. 306. DERS., Wikingerzeitliche und mittelalterliche Besiedlung am Ufer der Treene bei Hollingstedt (Kr. Schleswig-Flensburg) - Ein Flusshafen im Küstengebiet der Nordsee, in: Haithabu und die frühe Stadtentwicklung (wie Anm. 8), S. 83-105. H. ERLENKEUSER, ${ }^{14} \mathrm{C}$-Datierungen mittelalterlicher Plattformen am Ufer der Treene in Hollingstedt/Schleswig-Holstein, in: ebd., S. 107-115, hier S. 96-103. 
mit aktiver Unterstützung des Königs durch eine Modernisierung an die neuen Verhältnisse angepasst werden sollte. Aufgrund der archäologischen Funde in Schleswig und Lübeck lässt sich dabei für das beginnende 13. Jahrhundert der Schluss ziehen, dass diese Maßnahmen anfangs auch erfolgreich waren. ${ }^{148}$ Allerdings sollte auch in Betracht gezogen werden, dass der Handlungsdruck auf den dänischen König solange nicht besonders stark war, solange Hamburg und Hollingstedt unter seiner Macht standen. Spannend wurde das Verhältnis erst, als 1227 Hamburg und Lübeck aus dem Reichsverband ausscherten und damit einzig Hollingstedt/Schleswig als international bedeutende Häfen zurückblieben.

In die Zeit nach 1227 fallen in Schleswig vor allem die Veränderungen im Hafenbereich, die mit der Gründung des Dominikanerklosters auf einem Teil der alten Kaianlagen einhergingen. Diese wurden bisher immer dahingehend interpretiert, dass Valdemar Sejr den Schleswiger Hafen 1239 aufgegeben und als letzte resignierende Geste die Fläche den Mönchen überlassen habe. ${ }^{149}$ Doch erscheint dieses vor dem Hintergrund der handelspolitischen Lage unvertretbar, zumal, wenn man bedenkt, dass Lübeck und Hamburg zu diesem Zeitpunkt gerade erst dabei waren, ihren Transitweg endgültig abzusichern. So mag denn die Ansiedlung eines Klosters neuen Types am Schleswiger Hafen als Zeichen der Modernisierung interpretiert werden, das der sich abzeichnenden Krise entgegenwirken sollte, und welche durch Privilegierungen für die alten Handelspartner flankiert wurde. ${ }^{150}$ Zudem darf nicht vergessen werden, dass Bettelklöster im Allgemeinen und für Dänemark im besonderen als Urbanisierungskriterium gesehen werden, und zudem auch eine Gasthaus- und Hospitalsfunktion erfüllten. ${ }^{151}$

Allerdings baute der König nicht allein auf Schleswig, sondern versuchte, auch neue Transitrouten zu explorieren. $\mathrm{Zu}$ diesen Versuchen gehörten u. a. der Ausbau der Siedlung Hadersleben ${ }^{152}$ und der Aufbau neuer OstWesthandelsrouten nach Ripen/Ribe, welches nun die Rolle eines dänischen (Transit-)Westhafens übernahm. ${ }^{153}$ Ebenfalls um 1240 wurde die

\footnotetext{
${ }^{148}$ LÜDTKE, Keramik (wie Anm. 70), S. 130.

${ }^{149} \mathrm{Vgl}$. ausführlich JAHNKE. "... und er verwandelte“ (wie Anm. 108), S. $251 \mathrm{f}$. Die Rolle. die die Fahrwassertiefe in Schlei und Treene zur Entwicklung beigetragen hat, kann bis jetzt nicht beurteilt werden, da Untersuchungen, die über das Spekulative hinausgehen, bis jetzt nicht bekannt sind.

${ }^{150}$ HoffmanN, Schleswig und Lübeck (wie Anm. 4), S. 36.

${ }^{151}$ Anders ANDRÉN, Den urbana scenen, Malmö 1985, S. 58-63. Ich danke Frau Dr. Annette Frölich, Charlottenburg, für diesen Hinweis.

${ }^{152}$ Lennart MADSEN, De middelalderlige købstæder i Nordslesvig, in: Middelalderbyen, hg. von Søren Bitsch Christensen, Aarhus 2004, S. 97-112, hier S. 100-105.

${ }^{153}$ Siehe hierzu einleitend Per Kristian MADSEN, Ribe, a North Sea town and its Baltic relations. A survey of the long lines of the town's medieval trade, in: Exchange and Trade in
} 
Strecke Flensburg-Tondern/Leck als neue Ost-Westverbindung privilegiert. ${ }^{154}$ Gleichzeitig wurden u.U. auch andere Wege nach Schleswig gesucht, so z.B. über Rendsburg. Ebenso zogen flämische Kaufleute auch auf der Route Eider-Ostsee über Flemhude, wo 1242 eine Kirche errichtet wurde, entweder in Richtung des 1238/40 gegründeten Kiels oder aber nördlich in die königliche Stadt Eckernförde. ${ }^{155}$ Als Fazit dieser Entwicklungen erscheint der Eindruck, als ob nach 1227 versucht wurde, im geographisch günstiger gelegenen Herzogtum Schleswig eine Alternativroute zum Ost-Westhandel zu finden und entsprechend der südlicheren durch Privilegien abzusichern. Dieses Vorhaben wurde aber durch die nach dem Tode Valdemar Sejrs ausbrechenden Thronfolgekämpfe und die spätere Trennung des Herzogtumes von Dänemark nicht erfolgreich vollendet.

\section{Handel und Transport im Ostseeraum bis zur Mitte des 13. Jahrhunderts}

Wie aus dem Vorangehenden deutlich wurde, standen Schleswig/Hollingstedt und Lübeck/Hamburg seit Beginn des 13. Jahrhunderts in einer sich immer mehr verschärfenden Konkurrenz, einer Konkurrenz, die nach 1241 zugunsten Lübecks entschieden wurde. Diese Konkurrenz bedeutet nun aber nicht, dass die alten Kaufmannsgruppen zu Beginn des 13. Jahrhunderts schon aus dem Handel im Ostseeraum ausgeschlossen worden wären. Es kann vielmehr gezeigt werden, dass deutsche, skandinavische, gutnische, friesische, russische und slawisch-livische Kaufleute gleichermaBen und auf hohem Niveau miteinander und gegeneinander Handel trieben, wie besonders am Beispiel der Lübecker Zollrolle von 1222 und dem Schleswiger Stadtrecht aus dieser Zeit gezeigt werden kann, die diese Gruppen explizit erwähnen. ${ }^{156}$ Diese Verhältnisse blieben bis weit ins 13. Jahrhundert auch unverändert, wie die Greifswalder Zollrolle aus der Zeit

Medieval Europe, hg. von Guy de Boe und Frans Verhaeghe, (Papers of the ,Medieval Europe Brugge 1997' Conference, Vol. 3), Zellik 1997, S. $27-41$.

${ }^{154}$ Hans Friedrich SchüTT. Flensburg im Mittelalter, in: Flensburg, Geschichte einer Grenzstadt. Flensburg 1966, S. 21 ff.

155. Siehe Wolfgang LAUR, Historisches Ortsnamenlexikon von Schleswig-Holstein (Veröffentlichungen des schleswig-holsteinischen Landesarchivs, Bd. 28) Neumünster ${ }^{2} 1992$, S. 252, s. v. Flemhude. Rolf HAMMEL-KIESOw und Ortwin PELC, Landesausbau, Territorialherrschaft. Produktion und Handel im hohen und späten Mittelalter, in: Geschichte Schleswig-Holsteins. Von den Anfängen bis zur Gegenwart, hg. von Ulrich Lange, Neumünster 1996, S. 59-134, hier S. 125-128.

${ }^{156}$ HUB I, Nr. 223, S. 69f. AM ENDE, Verfassungsgeschichte (wie Anm. 66), S. 46f. Danmarks gamle Købstadlovgivning, Bd. I, Sønderjylland, hg. von E. Kroman und P. Jørgensen, København 1951, Slesvig I, §30, S. 9. Zu den russischen Kaufleuten siehe ANGERMANN, Novgorod (wie Anm. 19), S. 198f. 
um 1275 belegt, die Zölle für omnes Dani, Normanni, Sveci et omnes habitantes in Vemeren et in terra ducis [de] Sleswich, ,alle Dänen, Nortmänner [Norweger], Schweden und alle Einwohner Fehmarns und der Lande des Herzogs von Schleswig“, sowie alle Deutschen aus diesen Gebieten, die nicht Einwohner der entsprechenden Lande seien, festlegt. ${ }^{157}$ Generell kann aber konstatiert werden, dass die Bedeutung dieser anderen Gruppen für den Handel im Ostseeraum und speziell in den niederdeutschen Seestädten je weiter das Jahrhundert voranschritt umso mehr zurückging.

Die Gründe für dieses Zurückdrängen der fremden Kaufmannsgruppen aus dem später hansischen Handel des Ostseeraumes sind wiederum vielfältig. Als zwei der wichtigsten Gründe können das Einströmen neuen Kapitals in die Städte an der Küste des südlichen Ostseeraumes und die Veränderungen in den Transportmodalitäten angeführt werden.

Alle Bemühungen des dänischen Königs, seine Kaufleute gegen die neue Konkurrenz zu schützen, mussten letztendlich dort an ihre Grenzen stoßen, wo andere Kaufleutegruppen mit größerem Kapital, größerem Gewinn und größeren Absatzmöglichkeiten agierten, und dieses war vor allem das Kennzeichen der „,neuen“ deutschen Kaufleute ihrer Zeit. ${ }^{15 \mathrm{x}}$

Dieser Kapitalzufluss allein hätte aber nicht ausgereicht, um dem deutschen Kaufmann eine Vorrangstellung in den Seehäfen zu verschaffen. Hinzu kam eine Entwicklung im Bereich des Seetransportes, die wesentliche Auswirkungen hatte. Der Zustrom neuer Kaufleute in die Seehäfen des Ostseeraumes und die Ausweitung des Transportvolumens führte zwangsläufig zu einer Verknappung des zur Verfügung stehenden Transportraumes. Dieser Transportraum wurde anfangs von den skandinavischen, slawischen und anderen Schiffern bereitgestellt, ${ }^{159}$ Aristokraten, die

${ }^{157}$ HUB I, Nr. 746, S. 261 f. - Ebenso erscheinen Schleswiger und Flensburger Kaufleute 1259/60 im Rostocker Stadtbuch: Hii sunt de Sclezewic: Tote, Ewerleus, Geike, Willikinus, Gunne, Ecbertus, Bole, Heige, Vedderike, Halle, Ollavus, Perrus [?], Amec [?]. Hii sunt Flenseborch: Waleke, Ockke, Willikinus, Rike [?], Buwerne [?], Conradus, Bo[...]. Bucke, Petrus, Henricus, Boie. Hii omnes prescripti fideiusserunt pro hiis tribus captivis, quorum hec sunt nomina: Vederike, Scroder, Harr ..., Das Älteste Rostocker Stadtbuch, etwa 1254-1273, hrsg. v. Hildegrad Thierfelder, Göttingen 1967, I.2., § 101, S. 71. Siehe auch 1.3., § 115, S. 84: Ion et Take filius Thruwels, fratres de Buhovet [et] Mattes et Thruls, filii eorum, hii 4 fuerunt capitati, ubi concives nostri fuerunt eiectil?] de navibus, Hermannum [!] videlicet de Sleswic et suos socios 16. In die gleiche Richtung weist auch ein Eintrag im Stralsunder Stadtbuch aus dem Zeitraum zwischen 1288 und 1300: Euerhardus aduocatus emit racionabiliter nauem vnam de Johanne Boterman de Vlensborch coram consulibus, Das älteste Stralsundische Stadtbuch (1270-1310), hrsg. v. F. Fabricius, Berlin 1872, IV, § 226 , S. 87.

${ }^{158}$ S. HAMmEL-KIESOW, Determinanten (wie Anm. 22), im Druck.

${ }^{159} \mathrm{Zu}$ den Skandinaviern siehe EnGlert, Cargo Ships (wie Anm. 6), passim. Zum slawischen Schiffbau in Wollin bis ins 13. Jahrhundert siehe einleitend Władysław FILIPOWIAK, 
im Besitz eines Schiffes auch einen Prestigegegenstand sahen. Dementsprechend waren der Bau und die Ausstattung dieser Schiffe eine Spezialaufgabe, die viel Sachverstand voraussetzte. Die Anlage der neuen Städte nun führte zu der Möglichkeit, mehr Waren über das Meer transportieren zu können und damit zu cincm gestiegenen Bedarf an Schiffen, der durch die traditionellen Baumethoden und vor allem mit den vorhandenen Fachkräften nicht mehr adäquat gedeckt werden konnte, ein Vorgang, der sich beispielsweise in Italien und Byzanz am Beginn des 10. Jahrhunderts sehr genau beobachten lässt. ${ }^{|(\mid)|}$Die Lösung des Dilemmas lag im Ostseeraum wie in Byzanz darin, Bauformen zu schaffen, die weniger spezialisierte Arbeit verlangten. Es mussten Bauformen gefunden werden, bei denen nur die Schiffsform von Experten geplant und herausgearbeitet wurde, wohingegen die Außenhaut oder die inneren Versteifungen von angelernten Arbeitern angebracht werden konnten, oder aber, wo gelernte und ungelernte Arbeiter in einem Verbund zusammen arbeiten konnten. Dieses bedeutete eine erhebliche Kostenerleichterung und eine Erhöhung des Bautempos. Gleichzeitig begann man gleichzeitig damit, für die Außenhaut auch gesägte Bretter zu verwenden, was ebenfalls eine Kostenerleichterung bedeutete, da man größere Teile eines Baumes nutzen konnte. ${ }^{161}$

Als Konsequenz dieser Umstellung der Arbeitsmethoden wurden Reparaturen nicht mehr unbedingt von den Schiffseignern durchgeführt, sondern diese steuerten hierzu die Städte mit ihren Werften an. Gleichzeitig errichteten die Städte wiederum Anlagen, um den Schiffen das Anlanden in ihren Häfen zu erleichtern, um dadurch mehr Schiffe in ihre Häfen zu ziehen und damit das Transportvolumen zu erhöhen, das wiederum vom Transportraum abhängig war. Hierin kann man ebenfalls einen sich selbst verstärkenden Effekt sehen, der die neuen Handelsstädte in ihrer Bedeutung stützte.

Diese Entwicklung begünstigte den Bau und die Einführung jenes Schiffstypus', der in der deutschen Forschung gemeinhin unter dem

Die Häfen und der Schiffbau an der Odermündung im 9.-12. Jahrhundert, in: Untersuchungen zu Handel und Verkehr der vor- und frühgeschichtlichen Zeit in Mittel- und Nordeuropa, Teil V, Der Verkehr, hg. von Herbert Jankuhn, Wolfgang Kimmig und Else Ebel (Abhandlungen der Akademie der Wissenschaften in Göttingen, Phil-Hist. Klasse, Dritte Folge, Nr. 180), Göttingen 1989, S. 351-398, hier S. 360-367.

${ }^{16(1)}$ Richard UNGER. The ship in the Medieval Economy, 600-1600, London und Montreal 1980 , S. 104-113.

${ }^{161}$ Allerdings wurde dieses nicht konsequent so durchgeführt. Siehe Thorsten FöRSTER, Schiffbau und Handel an der südwestlichen Ostsee - Untersuchungen an Wrackfunden des 13.-15. Jahrhunderts, in: Schutz des Kulturerbes unter Wasser. Veränderungen europäischer Lebenskultur durch Fluß- und Seehandel (Beiträge zur Ur- und Frühgeschichte MecklenburgVorpommern, Bd. 35), Lübstorf 2000, S. 221-236. 
Begriff des Koggen gefasst wird. ${ }^{162}$ Allerdings sind rein terminologisch Zweifel daran angebracht, ob man die Quellen, die den Koggenbegriff vermitteln, mit der nun auftretenden unspezialisierten Bauweise zusammenbringen kann. ${ }^{163}$ Dieses wird durch eine Fälschung verdeutlicht, die das Domkapitel von Schwerin im Jahr 1209 anfertigen ließ. In eine Urkunde Heinrichs des Löwen aus dem Jahr $1171^{164}$ ließ das Kapitel folgende Rechtsverleihung einfügen und sich anschließend von Kaiser Otto IV. bestätigen $^{165}$ :

Cives Zuerinensis civitatis in omnibus locis per ducatum nostrum a teloneo liberi similiter erunt et exempti; ad usus etiam mercationum suarum in portu, qui Wissemer dicitur, duas magnas naves, que koggen appellantur, et minores quotcumque voluerint naves alias ... semper habebunt. ${ }^{166}$

„Die Einwohner Schwerins sind an allen Orten unseres Herzogtums vom Zoll befreit und ausgenommen; zudem soll [der Dom und das Domkapitel] zu seinem eigenen Handel in dem Hafen, der Wismar genannt wird, zwei große Schiffe, die Koggen genannt werden, und andere, kleinere Schiffe, wieviele sie auch immer haben wollen, ... auf ewige Zeiten [zollfrei] besitzen".

Der Inhalt der Fälschung deutet darauf hin, dass unter Koggen im Sinne der Urkundenschreiber kein Schiff besonderer Bauart verstanden wurde, was einen entsprechenden Sachverstand und die Kenntnis eines schiffbautechnischen terminus technicus des Domkapitels und des Schreibers vorausgesetzt hätte. Zudem hätte der Gebrauch eines schiffbautechnischen Begriffes die Gefahr in sich geborgen, dass das Privileg bei jeder Änderung der Bauweise hätte angezweifelt werden können oder das Domkapitel gezwungen gewesen wäre, auf veraltete Transportmittel zurückzugreifen, nur um sein Recht zu wahren. Ähnliches gilt für die sogenannten Ummelandfahrer-Privilegien von 1251, die ebenfalls explizit den Koggen erwähnen. ${ }^{167}$ Bei allen Bemühungen späterer dänischer Könige, die weitreichen-

${ }^{162}$ Die Bauweise des Koggen, d.h. ob bei ihm auf einem fertigen Innenskelett eine äußere Beplankung aus gesägten Brettern angebracht wurde, wie häufig behauptet, ist nach den neuesten archäologischen Erkenntnissen sehr umstritten. Höchstwahrscheinlich wurde auch der Koggen von außen nach innen gebaut. Ich danke Herrn Prof. Thijs Maarleveld in Esbjerg für diesen freundlichen Hinweis.

${ }^{163}$ Dieses wird auch dann deutlich, wenn der Bau von Kaianlagen in Lübeck eindeutig mit dem Auftreten des Koggen verbunden wird, wohingegen dieselben Kaianlagen in Schleswig unabhängig vom Schiffstyp resp. im Zusammenhang mit der skandinavischen Schifffahrt gesehen werden. Vgl. GLÄSER, Der Lübecker Hafen (wie Anm. 145), S. 54.

${ }^{164}$ MGH. DD, H.d.L., Nr. 89. S. 132-135.

${ }^{165}$ MUB I, Nr. 189, S. 179. und 202, S. 190-193.

${ }^{166}$ MGH. DD. H.d.L., Nr. 91, S. 138ff.

${ }^{167}$ Dipl. Dan. II. I, Nr. 50(-52), S. $50 \mathrm{ff}$. 
den ausländischen Privilegien auf den Schonischen Messen zu revidieren, wurde niemals darauf hingewiesen, dass die Zuiderzeestädte schon lange keine „Koggen“ (verstanden als Baubezeichnung) mehr benutzten. Auch muss man davon ausgehen, dass die Regelung, nach der der gefangene dänischc König Valdemar Sejr 1224 mit Koggen und Snicken zum Kreuzzug aufbrechen solle, wohl kaum dahingehend zu interpretieren ist, dass er wirklich Schiffe besonderer Bauart mit sich führen sollte. Es handelt sich hierbei wiederum nur um eine Aussage über die Schiffsgröße. ${ }^{168}$

Der Koggen erscheint in Schwerin, wie auch in anderen Zusammenhängen, als ein Schiff von besonderer Größe beziehungsweise mit besonders hoher Tragfähigkeit. Dieses korrespondiert mit anderen Umschreibungen für Koggen wie liburna und magna navis.

Dieser Zusammenhang wird durch eine Reihe von Zollbestimmungen bestätigt, die zugleich Auskunft darüber geben, ab wann ein großes Schiff zu einem Koggen wurde. Die Lübecker Zollrolle aus dem Jahr 1222 setzt die Grenzen für unterschiedliche Schiffszölle bei unter 5 Last, 5 bis 11 Last und ab 12 Last fest. ${ }^{169}$ Das rügische Fischereiprivileg für Lübeck aus dem Jahr 1224 unterscheidet weiterhin zwischen Schiffen von unter 12 Last, von 12 bis 18 Last und über 18 Last Tragfähigkeit, sufferenti. ${ }^{170}$ Aus den berühmten „Ummelandfahrer-Urkunden“ des Jahres $125 \mathrm{I}$ läßt sich dann die Schiffsgröße ermitteln, bei der aus einem Schiff ein Koggen wird. König Abel senkt für die Koggen, die um Skagen herum auf die Schonischen Messen kommen, den Zoll pro Koggen auf 32 Schilling Sterling. ${ }^{171}$ Andererseits waren dort $2 \emptyset r t u g{ }^{172}$ schonisch für eine Heringstonne zu zahlen. ${ }^{17}$ Das Ummelandfahrerprivileg stellte daher erst in dem Moment eine Zollerleichterung dar, wenn der „Koggen“ mehr als 10-12 Last Hering laden konnte. ${ }^{174}$ Korrespondierend mit den genannten Zollbestimmungen aus Lübeck lässt sich also festhalten, dass der in den frühen historischen Quellen belegte Koggen die Bezeichnung für ein Handelsschiff über 12 Last Tragfähigkeit war und, dass der in den schriftlichen Quellen der Zeit angeführte Begriff nicht unmittelbar als Zeichen einer bestimmten Bauart gedeutet werden kann.

\footnotetext{
${ }^{168}$ Dipl. Dan. 1.6, Nr. 16, S. 21-28, hier \$1, S. 24: et ibit ducens secum centum naues cockonibus et sneccis computatis.

${ }^{169}$ HUB I. Nr. 223, S. $69 \mathrm{f}$.

(70) UBStL 1, Nr. 27, S. $32 \mathrm{f}$.

${ }^{171}$ Dipl. Dan. 11.1. Nr. 50(-52), S. 50ff.

${ }^{172}$ Eine nordische Recheneinheit à $1 / 24$ Mark ( 1 Mark $=8$ Øre $=24$ Ørtug $=240$ Pfennig $=$ 960 Album). Ausgemünzt wurde der ørtug nur in Schweden im 14. Jahrhundert.

17.3 Carsten JAHNKE, Die Malmöer Schonenzolliste des Jahres 1375, in: HGbll. 115, 1997. S. I-107. hier S. 7.

17. Jahnke. Schonenzolliste (wie Anm. 174), loc. cit.
} 
Nun sind diese großen Schiffe keine deutsche Erfindung, sondern die archäologischen und dendrochronologischen Untersuchungen weisen eher darauf hin, dass der Bedarf an Schiffsraum zuerst von skandinavischer Seite aus gedeckt wurde, bis dann die Städte an der südlichen Ostseeküste ihre Werftkapazitäten so wcit ausgebaut hatten, dass sie selbst Schiffe in ausreichender Anzahl bauen konnten. In diesem Zusammenhang muss darauf hingewiesen werden, dass die frühen ,großen Schiffe“ in ihrer Tonnage und auch in ihren Segeleigenschaften ${ }^{175}$ den weiterentwickelten skandinavischen und wohl auch den slawischen Transportschiffen unterlegen waren. ${ }^{176}$

Klar wird an dieser Entwicklung aber auch, dass die Kaufleute der neuen Städte ihrem wichtigsten Transportmedium nur insofern Aufmerksamkeit schenkten, als es galt, die Baukosten zu senken. So ist es ein auffälliger Zug der Zeit, dass alle Schmuckformen, die die skandinavischen Schiffe bis dahin geprägt hatten, zugunsten einer nüchternen Sachlichkeit aufgegeben wurden, eine Tendenz, die auch dadurch verstärkt wurde, dass sich jetzt die Berufe des Schiffers und der des Kaufmannes voneinander trennten bzw. in diesen Städten wohl eher nie miteinander verbunden gewesen waren.

Das für die erste Hälfte des 13. Jahrhunderts gezeichnete Bild erscheint also als ein facettenreiches Mosaik verschiedenster Entwicklungen im Bereich der Städtewerdung, des Handels und des Transports. Von Lübeck und den deutschen Städten neuen Typs an der Südküste des Ostseeraumes aus strömten mehr und mehr Kaufleute mit größerem Kapital und einem weiten Absatzgebiet in das bestehende Handelssystem. Hier waren sie anfangs auf die Zusammenarbeit mit den etablierten Kaufleuten angewiesen. Diese Zusammenarbeit entwickelte sich in der ersten Hälfte des 13. Jahrhunderts zu einer Gleichberechtigung, deren Gewicht sich spätestens zur Jahrhundertmitte zugunsten einer deutschen Dominanz verschob, eine Abfolge, die auch am Beispiel des deutschen Einflusses auf Gotland und später am gotländischen Hof von Novgorod deutlich wird. ${ }^{177}$ Dieses ging mit einer sich selbst verstärkenden Rolle der Hafenstädte einher, die zu Lasten nichtstädtischer Landeplätze ging und die durch den Bau neuer

\footnotetext{
${ }^{179}$ Siehe hierzu H. BRANDT, K. HOCHKIRCH, The sailing properties of the Hanse cog in comparison with other cargo sailships (Ship Technology Research Vol. 42, No. 1), January 1995. zugleich http://pitcairn.tb12.tu-berlin.de/karsten/kogge/kogge.shtml, 9. November 2007. Des weiteren Detlev ElLMERS, Die Schiffe der Hanse und der Seeräuber um 1400, in: Störtebeker, 600 Jahre nach seinem Tod. hg. von Wilfried Ehbrecht (Hansische Studien, Bd. XV), Trier 2005, S. 153-168, hier S. 154.

${ }^{176}$ Anton ENGLERT, Large Cargo Vessels in Danish Waters, AD 1000-1250, Diss. phil. Kiel, 2000.

${ }^{177}$ KatTinger, Gotländische Genossenschaft (wie Anm. 9), passim.
} 
Schiffstypen unterstützt wurde. Dieser Prozess vollzog sich langsam, wurde vor allem durch die dänische Friedensperiode bis 1226/7 bestärkt und gewann nach 1227 eindrücklich an Geschwindigkeit.

In dieser Zeit änderten sich nicht nur die Routen des Fernhandels, auch die regionalen Subsysteme im Ostsceraum wurden jetzt, zu Beginn des 13. Jahrhunderts, neu ausgerichtet. Das Aufblühen größerer Handelshäfen bedingte gleichzeitig den Aufbau von regionalen Handelsverbindungen, zu Land und zu See, die die Versorgung der großen Zentren sichern sollten und die gleichzeitig als Absatzgebiete fungieren konnten. In diese neuen regionalen Handelssysteme wurden selbstverständlich auch die schon bestehenden Kaufmannsgruppen im Ostseeraum miteinbezogen, deren Bedeutung zumindest im regionalen Bereich auch über das 13. Jahrhundert hinaus erhalten blieb. Als Indizien für den Aufbau dieser neuen Systeme können wiederum die Städtegründungen bzw. - umbauten entlang und im Hinterland aller Küsten des Ostseeraumes dienen. Die Einbindung dieser Unterzentren in die neuen Handelsströme lässt sich dabei zum Beispiel an der Verbreitung neuer Keramiktypen veranschaulichen, die, wie jetzt das Beispiel der dänischen Stadt Næstved zeigt, parallel zur Handelsentwicklung nachzuweisen ist. ${ }^{178}$ Andere Hinweise für die Neustrukturierung der Handelsnetze liefert die Verbreitung des lübischen Rechtes, das noch im 13. Jahrhundert u. a. Wittenburg, Plön, Bad Oldesloe, Itzehoe, Kiel, Eutin und Wilster verliehen wurde, Städte, deren Handel auf Lübeck ausgerichtet war. Aber auch der Umschlag regionaler Produkte in Lübeck zeugt von diesem neuen Netz: so wurde z. B. der Hopfen aus Brandenburg und dem Wendland, d.h. aus Parchim, Schwerin, Kriwitz, Brüel, Sternberg, Goldberg, Neustadt/Dosse, Grabow oder Wittenburg nach Lübeck gebracht, ${ }^{179}$ oder importierte die Stadt Getreide und andere Nahrungsmittel aus Schleswig-Holstein ebenso wie aus Dänemark. ${ }^{180}$

\section{Epilog}

Nach 1240/50 kann von einer Dominanz Lübecks und der anderen neuen Städte entlang der Ostseeküste gesprochen werden. Allerdings bedeutete diese Dominanz keine Monopolstellung im Ostseeraum. Vielmehr versuchten die alten Kaufleutegruppen noch bis ans Ende dieses Jahrhunderts, ihre Position zu verteidigen resp. zurück zu gewinnen, wie anschaulich am

\footnotetext{
${ }^{178}$ Ich danke Herrn Jesper Langkilde für seine Hinweise auf die neuen, bisher unveröffentlichten Næstveder Untersuchungen.

${ }^{179}$ FrontzeK. Braugewerbe (wie Anm. 144), S. 43 mit weiteren Belegen.

${ }^{180}$ HyBEL und POULSEN, The Danish resources (wie Anm. 144), S. 241 f., $253 \mathrm{ff}$. und passim.
} 
Beispiel der Stadt Schleswig und der Knudsgilden deutlich gemacht werden kann.

Schleswig, im Verbund mit Flensburg und anderen Städten, versuchte noch im dritten Viertel des 13. Jahrhunderts, durch Privilegien und den Zusammenschluss ihrer Kaufleute der Konkurrenz Einhalt zu gebieten. Von Seiten des Landesherrn in ungesehener Weise gefördert, erhielt die Stadt 1252 die Freiheit von allen Zöllen und Handelsabgaben im ganzen Reich, ${ }^{181} 1261$ zwei neue Märkte in der Stadt, ${ }^{182} 1264$ die Bestätigung der Abgabenfreiheit im Herzogtum Jütland, ${ }^{183} 1272$ die königliche Stadtsteuer. das arnegæld, erlassen, ${ }^{184} 1282$ die vollständige Zollfreiheit auf den Schonischen Messen, ${ }^{185} 1284$ und 1286 die Bestätigung des freien Handels im Herzogtum Jütland ${ }^{186}$ und 1289 noch einmal die Befreiung von allen Zöllen in Dänemark bestätigt. ${ }^{187}$

Ebenso wichtig wie die Privilegien waren aber auch Versuche der dänischen Kaufleute, sich in gleicher Weise wie ihre deutschen Konkurrenten zu einer durchsetzungskräftigen Einheit zusammenzuschließen. Hier können vor allem Schleswig und Flensburg als Vorreiter angesehen werden, deren Kaufleute sich 1282 zu einer Gemeinschaft zusammenschlossen, deren Grundzüge große Ähnlichkeiten mit den ersten hansischen Bündnissen aufweist: Bürger sollen nur vor den städtischen Gerichten angeklagt werden können, gegenseitige Hilfe der Bürger bei Schiffbruch soll gewährleistet werden, auch sollen das Verbot des Vorkaufes samt Regularien zur Beilegung gegenseitiger Anklagen dieses Bündnis befestigen. ${ }^{188}$

Auch reagierten die dänischen Knudsgilden auf die veränderte Situation, indem sie zu einem unbekannten Zeitpunkt zwischen 1237 und 1250 ihre Generalsynode auf die Schonischen Messen, eben einen der neu entstandenen Kontaktpunkte des internationalen Handels, verlegten. ${ }^{89}$ Die Gilden reagierten aber nicht nur durch eine geographische Neuausrichtung, sondern auch, indem sie sich u.a. zu einer Seeversicherung und Kaufmannsabsicherung modernsten Types entwickelten. ${ }^{190}$ So sehen u.a.

${ }^{181}$ Dipl. Dan. II.1, Nr. 72, S. 68f., s. a. Nr. 28, S. 28.

${ }^{182}$ Dipl. Dan. II.I, Nr. 330, S. 254 f.

${ }^{183}$ Dipl. Dan. II.1, Nr. 424, S. 327 f.

${ }^{184}$ Dipl. Dan. II.2, Nr. 199. S. $179 \mathrm{f}$.

${ }^{185}$ Dipl. Dan. II.3, Nr. 53. S. 58 f. Dieses Recht wurde nur 1283 Ripen, um diese Zeit Stege, 1287 Riga und 1322 Halmstadt verliehen.

${ }^{186}$ Dipl. Dan. II.3, Nr. 87, S. 98 und II.3, Nr. 223, S. 188 f.

${ }^{187}$ Dipl. Dan. 11.3. Nr. 351, S. 299f. Siehe JAHNKE, ,... und er verwandelte" (wie Anm 108), S. $262 \mathrm{f}$.

${ }^{188}$ Diplomatarium Flensburgense, Samling af Aktstykker til Staden Flensborgs Historie indtil Aaret 1559, hg. von H.C.P. SEJDLIN, København 1865, Nr. 3, S. 11 f.

${ }^{189}$ GILKÆR, In honore (wie Anm. 112), S. 140.

190 JAHNKE, Skånemarkedet, Knudsgilderne og international handel i det 12. og 13. århundrede, im Druck. GILKAER, In honore (wie Anm. 112), S. 141 und passim 
die Flensburger Statuten der Knudsgilde aus dem 13. Jahrhundert vor, dass Brüder bei Schiffbruch sich gegenseitig tatkräftig und finanziell helfen, ihre Brüder aus der Gefangenschaft anderer befreien, bei Verlust von Gütern finanzielle Hilfe leisten und diejenigen Brüder strafen sollten, die mit Piraten gemeinsame Sache machten. ${ }^{191}$ Aus diesen Artikeln ist sehr deutlich das Bemühen der dänischen Kaufleute abzulesen, der aufstrebenden Konkurrenz aus dem Süden durch moderne Organisationsformen entgegenzuarbeiten, Formen, die, wie zum Beispiel die Seeversicherung, moderner waren, als die der hansischen Zusammenschlüsse.

Auch verlor die Stadt Schleswig nicht völlig ihre Funktion als Transithafen. So baten noch $1265^{192}$ und $1284^{193}$ bremische Kaufleute vor Ort um Geleit und Schutz durch den Landesherrn, da sie ad civitatem nostram Sleswik vel ad alias quascumque partes ductus nostri cum mercibus suis pacifice venire voluerint, ,in unsere Stadt Schleswig oder in andere Teile unseres Herzogtumes mit ihren Handelswaren in Frieden ziehen", bzw. ad civitatem Slceswik veniendi vel recedendi, ,in die Stadt Schleswig kommen und gehen" wollen, doch war das nur noch eine schwache Reminiszenz vergangener Größe.

Am Ende war die Kapitalkraft der deutschen Kaufleute und die Anziehungskraft der südlichen und östlichen Ostseestädte um ein Vielfaches größer geworden, so groß, dass den skandinavischen, gutnischen und anderen Kaufleutegruppen nur noch übrig blieb, sich jetzt ihrerseits in das neu entstandene Handelssystem einzugliedern.

\section{Zusammenfassung}

Die Veränderungen, die den Handel im Ostseeraum im Verlaufe der 12. und 13. Jahrhunderts prägten, lassen sich auf keinen Fall monokausal mit der „Stadtgründung“ Lübecks oder dem springflutartigen Einströmen deutscher Kaufleute in diesen Raum begründen. Es konnte vielmehr gezeigt werden, dass die sächsischen und westfälischen Kaufleute, die an die Ostseeküste kamen, sich dort allein aus praktischen Überlegungen heraus in die bestehenden Systeme integrieren mussten. Die Rolle Schleswigs und die der alten Handelsmächte geriet daher im Laufe des 12. Jahrhunderts nur sehr langsam in Gefahr. Die eigentliche und wesentliche Veränderung, zumindest was die Transportwege anbelangt, geschah dann erst zwischen 1201 und 1241, als Lübeck und Hamburg, die beide nicht als Transithäfen gegründet worden waren, den Transithandel zwi-

${ }^{191}$ Dipl. Flensb. (wie Anm. 188), Nr. 1, S. 1-10, hier S. 4.

${ }^{192}$ Dipl. Dan. II.1, Nr. 490, S. 325. Brem. UB 1. Nr. 320, S. 358f.

${ }^{193}$ Dipl. Dan. II.3, Nr. 100, S. 93. Brem. UB I, Nr. 419, S. 451. 
schen Ost- und Nordsee mit dem Ausbau der „Hamburger Straße“ entwickelten.

Die Neuordnung des Handelsnetzes im Ostseeraum geschah in der ersten Hälfte des 13. Jahrhunderts, als der alte Handelsweg NovgorodSchleswig-Westen von Süden durch die Stadıneugründungen und von Norden durch die Ummelandfahrt der Nordseeanrainer bis auf die Schonischen Messen von zwei Seiten in Frage gestellt wurde. Ausschlaggebend für den Erfolg vor allem der neuen Städte an der Südküste der Ostsee war wohl die Kapitalkraft der neuen Kaufleute, die frisches Kapital in den Handel einströmen ließ, und die besseren Rechtsverhältnisse, die die Kaufleute in den Städten deutschen Rechts vorfanden; die gleichen Gründe, die auch für die Ausbildung der geographisch schlecht platzierten Handelsstraße zwischen Lübeck und Hamburg angeführt werden können.

Mit der Ausbildung des neuen Städtenetzes und den gesteigerten Absatzmöglichkeiten baltischer Waren ging ein steigender Bedarf an Transportkapazitäten einher, der durch Vereinfachungen in der Konstruktionsweise von Schiffen und den Bauabläufen auf Werften einherging. Der spezialisierte Schiffbau der Wikingerzeit, in der prestigeträchtige und reich verzierte Schiffe für selbständige Schiffer-Kaufleute gebaut wurden, ${ }^{194}$ wurde um 1200 von einer durch angelernte Arbeiter ausführbaren nüchternen Produktion abgelöst, ${ }^{195}$ in der ein neuer Schiffstyp entstand, der gemeinhin mit dem Aufstieg der Hansestädte verbunden wird, wohl aber als Folge ihres Aufstieges zu sehen ist. Ob dieser neue Schiffstyp als Koggen bezeichnet wurde, oder ob Koggen nur ein Begriff für ein Schiff über 12 Lasten Tragfähigkeit ist, ist noch zu klären, es deutet aber vieles darauf hin, dass die Bezeichnung Koggen kein terminus technicus für eine bestimmte Bauart, sondern nur für die Tragfähigkeit war.

Die alten Kaufleutegruppen im Ostseeraum verschwanden nicht von einem auf den anderen Tag aus dem Handel in diesem Gebiet. Sie standen vielmehr in einer gegenseitigen Wechselbeziehung zu den neu eingewanderten Kollegen aus dem Süden. Anfangs, im 12. Jahrhundert, mussten die niederdeutschen Kaufleute sich in die bestehenden Systeme integrieren, um ihre Waren überhaupt absetzen und erwerben zu können. $\mathrm{Zu} \mathrm{Beginn}$ des 13. Jahrhunderts kooperierten die einzelnen Gruppen auf gleicher Augenhöhe miteinander, ein Verhältnis, das Mitte des Jahrhunderts durch

${ }^{194}$ Siehe einleitend Jan BILL, Getting into business. Reflections of a market economy in medieval Scandinavian shipbuilding, in: Shipshape, Essays for Ole Crumlin-Pedersen, hg. von Olaf Olsen, Jan Skamby Madsen und Flemming Rieck, Roskilde 1995, S. 195-202, hier S. 195ff. Siehe ebenfalls Björn VARENIUS, Det nordiska skeppet. Teknologi och samhällesstrategi i vikingatid och medeltid (Stockholm Studies in Archaeology, Vol. 10), Stockholm 1992, S. $131 \mathrm{ff}$. und passim.

${ }^{195}$ BILL. Getting into business (wie Anm. 195), S. $201 \mathrm{f}$. 
eine Dominanz der deutschen Kaufleute abgelöst wurde, mit der sich nun wiederum die skandinavischen Kaufleute arrangieren mussten.

Die skandinavischen Kaufleute und auch das Königtum sahen dieser Entwicklung nicht tatenlos zu, sondern versuchten, durch ein Bündel von Privilegierungen und Modernisierungsmaßnahmen mit der Entwicklung Schritt zu halten. Auch die Kaufleute selbst versuchten, durch Bündnisund Gildenbildung, ein Gegengewicht zu schaffen. Allerdings konnten diese Maßnahmen nicht das Kapital für den Handel bereitstellen, welches durch die bedeutenden Absatzmärkte und die Integration der Ministerialen in den deutschen Handel plötzlich bereitstand. Dieser neue Kapitaleinschuss kann m. E. als einer der Hauptgründe für den Erfolg des deutschen Kaufmanns in den so genannten Neusiedelgebieten aufgefasst werden.

Die zweite "Stadtgründung“ Lübecks $1158 / 59$ ist nur eine Etappe auf dem langen Weg zwischen 1100 und 1250. Die Bedeutung dieser Stadt liegt nicht in ihrer Gründung selbst, sondern darin, dass mit Hamburg ein leistungsfähiger Gegenhafen entstand, und dass Lübecker Kaufleute die Transitroute zwischen beiden Städten entwickelten. Die Impulse zur Neuordnung der Handelsstrukturen im Ostseeraum kamen also nicht 1158/59, sondern sind in der Zeit nach 1188/89, vor allem aber in der ersten Hälfte des 13. Jahrhunderts zu suchen. Die wirklich wichtigen und messbaren Veränderungen konzentrieren sich alle in den Zeitraum zwischen 1201 und 1241. In dieser Zeit wurden die Weichen in eine Richtung gestellt, die bis zum Ausgang des 19. Jahrhunderts diesen Raum prägen sollte. 